NASA Technical Memorandum 82891

\title{
Summary and Recent Results \\ From the NASA Advanced \\ High-Speed Propeller \\ Research Program
}

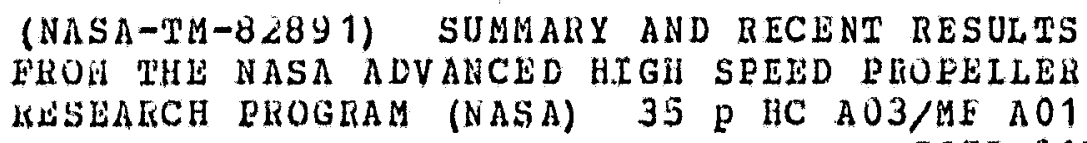

Glenn A. Mitchell and Daniel C. Mikkelson

Lewis Research Center

Cleveland, Ohio

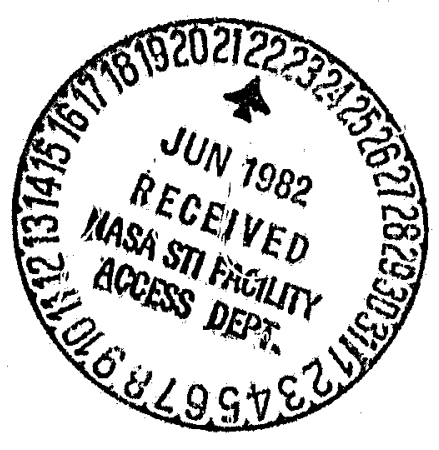

Prepared for the

Eightee!th Joint Propulsion Conference

cosponsored by the AIAA, SAE, and ASME

Cleveland, Ohio, June 21-23, 1982

\section{NRSA}




\title{
SUMMARY AND RECENT RESULTS FROM THE NASA ADVANCEO HIGH-SPEED \\ PROPELLER RESEARCH PROGRAM
}

\author{
Glenn A. Mitchell and Daniel C. Mikkelson \\ National Aeronautics and Space Administration \\ Lewis Research Center \\ Cleveland, Ohio 44135
}

\begin{abstract}
Advanced high-speed propellers offer large performance improvements for aircraft that cruise in the Mach 0.7 to 0.8 speed regime. At these speeds, studies indicate that there is a 15 to 35 percent block fuel savings and associated economic benefits for advanced turboprops compared to equivalent turbofan powered aircraft. The current status of the NASA research program on high-speed propeller aerodyryamics, acoustics, and aeroelastics is described. Recent wind tunnel results for five 8- to 10-blade advanced models are compared with analytical predictions. Test results show that blade sweep was important in achieving net efficiencies near 80 percent at Mach 0.8 and reducing near-field cruise noise by $6 \mathrm{~dB}$. Lifting line and lifting surface aerodynamic analysis codes are under development and some initial lifting line results are compared with propeller force and probe data. Some initial laser velocimeter ineasurements of the flow field velocities of an 8-bladed $45^{2}$ swept propeller are shown. Experimental aeróelastic results indicate that cascade effects and blade sweep strongly affect propeller aeroelastic characteristics. Comparisons of propeller near-field noise data with linear acoustic theory indicate that the theory adequately predicts near-field noise for subsonic tip speeds but overpredicts the noise for supersonic tip speeds. Potential large gains in propeller efficiency of 7 to 11 percent at Mach 0.8 may be possible with advanced counter-rotation propeliers.
\end{abstract}

\section{INTRODUCTION}

The free air propeller offers the potential of very high propulsive efficiencies for aircraft that operate at subsonic speeds. To address this key propulsion component NACA/NASA has conducted propeller research programs during much of the history of the agency. From 1927 to about the mid 1950's NACA had an extensive propeller research program. This research led to many successful propeller powered aircraft that operated at cruise speeds up to as high as Mach 0.6. From the mid 1950's to the mid 1970's there was about a 20-year hiatus in propeller research due to the success of turbojet and turbofan propulsion systeiis. These systems offered efficient flight at speeds from Mach 0.6 to 0.85 with cruise altitudes above most of the weather. Although the propulsive efficiencies of these systems were much lower than the early turboprops, this disadvantage was more than overcome by the very low fuel costs (near 10 cents per gallon). When the world energy crisis started in 1973 and 1974, NASA started an initial modest effort to re-evaluate the need for a propeller research program. Both inhouse and contractor studies indicated that there is a large performance advantage at cruise speeds up to Mach 0.8 for advarced high-speed turboprop powered aircraft compared to equivalent technology high bypass ratio turbofans. These advantages could 
result in large block fuel savings, reduced life cycle costs, improved range, or other benefits for both future civil and military aircraft. To investigate these advantages a high-speed propeller research program was established at the NASA Lewis Research Center in 1976. Over the past six years a number of advanced high-speed propeller models have been tested. Results from these tests have shown that high propeller efficiencies can be obtained at cruise speeds up co at least Mach 0.8. Also, significant reductions in propeller noise have been demonstrated at cruise conditions.

\section{ADVANCED TURBOPROP POTENTIAL}

The attractiveness of advarced turboprop propulsion results from its potential for very high propulsive efficiency at cruise speeds up to Mach 0.8. A comparison of the installed cruise efficiency of turboprop-powered and turbofan-powered propulsive systems is shown in figure 1 over a range of cruise speeds. The efficiencies shown in the figure include the instaliation losses for both systems; namely, nacelle drag for the turboprop systems, and cowl drag and internal airflow losses for the turbofan systems. Conventional general aviation turboprops have installed efficiency levels near 80 percent up to about Mach 0.5 but suffer from rapid decreases in efficiency above this speed due to increasing propeller compressibility losses. These losses are primarily the result of relatively thick blades ( 5 to 7 percent at 75 percent radius) operating at high helical tip Mach numbers.

The advanced high-speed turboprop has the potential to delay these compressibility losses to a much higher cruise speed and achieve a relatively high performance to at least Mach 0.8 cruise. Although high bypass ratio turbofans exhibit their highest efficien:y at cruise speeds near Mach 0.8 , their performance would still be significantly below that of the advanced turboprops. At Mach 0.8 the installed efficiency of turbof an systems would be approximately 65 percent compared to about 75 percent for the advanced turboprop. At lower cruise speeds, the efficiency advantage of the advanced turboprop would be even larger.

A number of studies have been conducted by both NASA and industry to evaluate the potential of advanced high-speed turboprop propulsion for both civil and military applications. Numerous references to specific studies and summary results are listed in reference 1. The trip fuel savings trend shown in figure 2 plotted versus operating range is a summary of these studies. Installed efficiency levels similar to those shown in figure 1 for comparable technology advanced turboprops and turbofans were used in most of these studies. As shown in figure 2, trip fuel savings is dependent on aircraft cruise speed and range. At the bottom of the band, associated with Mach 0.8 cruise, fuel savings range from about 15 to 30 percent for advanced turboprop aircraft compared to equivalent technology turbofan aircraft. The larger fuel savings occur at the shorter operating ranges where the mission is climb and descent dominated. Because of the lower operating speeds encountered during climb and descent, turboprops have an even larger performance advantage than the advantage at Mach 0.8 cruise conditions. In a similar manner, a larger fuel savings is possible at Mach 0.7 cruise (represented by the top of the band in fig. 2). At this lower cruise speed fuel savings range from 25 to near 40 percent. Evell larger fuel savings may be possible by recovering the propeller swirl loss from these single rotation turbcorops. Counter rotation is one promising concept for recovering swirl loss that is currently under study at NASA Lewis and, through a contracted program, at Hamilton Standard. 


\section{AUVANCED UESIGN CONCEPTS}

A model of an advanced high-speed turboprop propulsion system is shown in figure 3. The advanced propeller would be powered by a modern turboshaft engine and gear box to provice the maximum power to the propeller with a minimum engine fuel consumption. Propeller efficiency would be kept high by minimizing or eliminating compressibtlity losses. This would be accomplished by utilizing thin swept blades that would be integrally designed with an area ruled spinner and nacelle. Blade sweep would also be used to reduce noise during both take-off/landing and during high-speed cruise flight (refs. 1 to 3). Aircraft operations at high altitudes and Mach 0.6 to 0.8 requires much higher power than used on current propeller aircraft. A power loading (sliaft horsepower divided by propeller diameter squared) about three to four times higher than existing technology low-speed turboprops would be needed to minimize propeller aiameter and weight. Eight or ten blades are required to increased ideal efficiency at these higher disk loadings. In addition to these advariced concepts, a modern blade fabrication technique is needed to construct the thin, highly swept and twisted blades.

Since all of the advanced concepts used to minimize compressiblitiy losses are interrelated, an integrated procedure is used to design high-speed propellers and nacelles (refs. 1 and 4). The effects of applying these advanced concepts to a propeller design are shown in figure 4 . This figure is based on a cruise condition of Mach 0.8 and shows the propeller blade Mach number as it varies from hub to tip. The Mach number at each radial location is called the section Mach number and is the vector sum of the axial and rotational components. Curve A represents the Mach number distribution encountered by the propeller operating in an unsuppressed flow field where the axial component is the free-stream Mach number. At the hub the section llach number is slightly higher than the cruise speed of Mach 0.8. As the rotational velocity component becomes larger at increased radius, the relative Mach number increases until it reaches Mach 1.14 at the blade tip. This Mach number inust be compared to the drag rise (or drag divergence) Mach number of each blade airfoil section to evaluate the propelier performance potential. The predicted drag rise Mach number (fig. 4, curve B) was obtained from isolated two-dimensional airfoil data for a high-speed propeller having thicknessto-chord ratios of about 15 percent at the hub and 2 percent at the 1 lade tip. Across the entire radius the section Mach number (curve $A$ ) is higher than the drag rise Mach number (curve B). This represents a potentialiy large compressibility loss.

The advanced aerodynamic concepts of thin swept blades and an area ruled spinner and integrated nacelle design are effective in minimizing or eliminating these losses. In the outer portions of the propeller, the thin bliades are swept to reduce the component of velocity normal to the blade airfoil section, similar to swept wing theory. With a sufficient amount of sweep the section Mach number (curve A) can be reducea to an effective Mach number (curve $C$ ) that is below the drag rise Mach number (curve $B$ ) in the outer portions of the blade. This procedure significantly reduces the compressibility losses in the blade tip region and can also be effective in reducing noise. In the hub region, the spinner-nacelle body is tailored to increase the effective nacelle blockage behind the propeller and reduce the local Mach number through the propeller plane. This effect is shown by the local surface Mach number distribution plotted in figure 4 and the resulting effective section Mach number of curve $D$. Near the hub the effective section Mach number is suppressed far below the drag rise Nach number. With a large number of 
blades ( 8 in this example), the hub blade sections operate as a cascade and the additional Mach number suppression is necessary to prevent blade-to-blade choking. Area ruling the spinner between the blades gives further relief from choking by opening the flow area between the blades at the spinner.

In addition to maximizing the aerodynamic performance of the advanced turboprop, tecinniques for minimizing the near-field source noise during cruise operation have been developed to keep interior noise levels competitive with current wide body aircraft and to minimize the need for fuselage acoustic treatment. Since the blade relative tip Mach numbers are slightly supersonic as shown in figure 4 (MTIP $\approx 1.14$ ) the initial approach for noise reduction was to add sweep and reduce the effective local section Mach number to below the section critical Mach number. The shock strength and, therefore, the resulting pressure pulse is thereby reduced. The initial blade designs with $30^{\circ}$ tip sweep were expected to be somewhat guieter for this reason. A more advanced concept was incorporated in a $45^{\circ}$ tip sweep design (SR-3) using the linear acoustic analysis of reference 5 . A historical development of the application of acoustic theory to advanced propeller design is given in reference 6 . The present theory predicts thickness (due to blade airfoil thickness distribution) and loading (due to pressure loads on the blade airfoil) noise components from each radial section of the blade. Thickness noise is generally the dominant noise source on a propeller operating with a slightly supersonic tip Mach number. By properly sweeping and stacking the blade it is possible to reduce near-field noise using the phase interference concept illustrated in figure 5 . The noise from one propeller blade is the vector sum of the contributions of the sinusoidal wave (amplitude and phase angle) from each radial strip. The noise of the total propeller is the product of the vector sum and the number of b:ades. Sweeping the tip back causes its signal to lag (increased phase angia) the signal from the mid-blade region thus causing partial interference and a reduction in noise. This phase interference concept was used in the acoustic design of the $45^{\circ}$ swept propeller model (SR-3) to reduce the near-field cruise noise. This concept should have application to both thickness and loading noise in the near and far fields.

\section{PROPELLER MODEL DESIGNS}

In a cooperative program between NASA-Lewis Research Center and Hamilton Standard the concepts described above were used to design a series of propeller models for wind tunnel testing. The basic blade planforms pictured in figure 6 represent five propeller designs that have been wind tunnel tested. All of the propellers shown in the figure except the fourth one (SR-6) were designed by Hanilton Standard. The SR- 6 was aerodynamically designed at the Lewis Research Center. The first three propellers shown in the figure (SR-2, $S R-1 M$, and $S R-3)$ have a blade tip speed of $244 \mathrm{~m} / \mathrm{sec}(800 \mathrm{ft} / \mathrm{sec})$, a cruise power loading of $301 \mathrm{~kW} / \mathrm{m}^{2}\left(37.5 \mathrm{hp} / \mathrm{ft}^{2}\right)$ at Mach 0.8 and $10.668 \mathrm{~km}$ $(35000 \mathrm{ft})$, and 8 blades. The last two propellers shown are 10-bladed models. The SR-6 has a design blade tip speed of $213 \mathrm{~m} / \mathrm{sec}(700 \mathrm{ft} / \mathrm{sec})$, and a cruise power loading of $241 \mathrm{~kW} / \mathrm{m}^{2}\left(30 \mathrm{hp} / \mathrm{ft}^{2}\right)$; and the SR-5 has a design blade tip speed of $183 \mathrm{~m} / \mathrm{sec}(600 \mathrm{ft} / \mathrm{sec})$ and a cruise power loading of 209 $\mathrm{kW} / \mathrm{m}^{2}\left(26 \mathrm{hp} / \mathrm{ft}^{2}\right)$. The blade planforms are identified by tip sweeps of $0^{\circ}, 30^{\circ}, 45^{\circ}, 40^{\circ}$, and $60^{\circ}$. Here the tip sweep is approximately the angle between the blade mid-chord line at the tip of the blade and a radial line intersecting this line at the tip. 
The straight blade and an inftial $30^{\circ}$ swept blade (not shown) were designed using established analyses (ref.7) that lack a refined methodology to design the twist of a swept blade. Tests of the initial $30^{\circ}$ swept design indicated a retwist was required (which was actually a redistribution of the blade load from hub to tip). That became the modified $30^{\circ}$ swept design shown in figure 6 (SR-1M). The $45^{\circ}$ and $60^{\circ}$ swept blades (SR-3 and SR-5) were designed for acoustic suppression as well as improved aerodynamic performance by tailoring the sweep and planform shape as described in reference 8 . The Lewis propelier design (SR-6) was based on a different design philosophy, wherein the cruise design conditions were changed from those used for the first three propellers in order to increase predicted performance and lower noise. The design tip speed of this propeller was lowered to help reduce noise. The predicted performance lost by the lower tip speed was regained and possibly increased slightly by increasing the number of blades to 10 and lowering the power loading to $241 \mathrm{~kW} / \mathrm{m}^{2}\left(30 \mathrm{hp} / \mathrm{ft}^{2}\right)$. The technique of lowering tip speed and power loading was also used with the SR-5 design. Its design point was chosen to further reduce noise and obtain about the same predicted performance level as the 8-bladed modeis. More detailed discussions of the aero/acoustic design methodology represented by the SR-3 and SR-5 designs are presented in references 5,6 , and 9 .

The noise levels that were predicted at the time these blades were designed are listed in figure 6 . The cruise noise predictions indicated a small 1 reduction for $30^{\circ}$ of sweep, a significant reduction for the aero/acoustic $45^{\circ}$ swept design and the $40^{\circ} 10-b l a d e d$ design and a very large reduction for the $60^{\circ} 10-$ bladed design.

Each photograph in figure 7 shows one of the five propeller models that was installed on the Propeller Test Rig (PTR) in the NASA-Lewis 8-by 6 foot wind tunnel. The tunnel (ref. 10) has a porous wall test section to minimize any wall interactions. The PTR is powered by a $746 \mathrm{~kW}(1000 \mathrm{hp})$ air turbine using a continous flow $3.1 \times 10^{6} \mathrm{~N} / \mathrm{m}^{2}$ (450 psi) air systen routed through the support strut. Axial force and torque on the propeller are measured on a rotating balance located inside of an axisymmetric nacelle behind the propeller (ref. 8).

\section{PROPELLER AERODYNAMIC RESEARCH}

Experimental wind tunnel test results obtained with the 8-bladed propellers (refs. $1,4,8,11$ ) are summarized in figure 8 . The net efficiencies of the $0^{\circ}, 30^{\circ}$, and $45^{8}$ swept blade designs are shown for Mach numbers from 0.6 to 0.85 . Because the power coefficient and advance ratio are constant in this figure, the ideal efficiency is also constant as is shown by the upper dashed line. The ideal efficiency represents the performance of an optimally loaded propeller with no blade drag. The difference in figure 8 between the ideal efficiency line and the experimental performance curves represents the viscous and compressibility losses. As the data curves show, those losses increase at the higher speeds due to increasing compressibility losses. However, the performance of the $45^{\circ}$ swept blade decreased a smaller amount with increasing speed than the performance of propellers with less sweep. The $45^{\circ}$ swept blade achieved a 3 percent performance gain over the straight blade design at Mach 0.8 and about a 4 percent gain at Mach 0.85 . At the lower speeds of Mach 0.6 to 0.7 both swept blades had approximately a 2 to 3 percent efficiency advantage over the straight blade and the highest performing design had an efficiency that exceeded 81 percent. At speeds near Mach 0.6 the straight blade design may not have had an optimum wwist distribution. 
Unpublished data with ar identical blade shape constructed from graphite rather than steel (that apparently deflected to a more optimum twist distribution) had a net efficiency near the $45^{\circ}$ swept design at Mach 0.6. The study level (shown on fig. 8) of 79.5 percent efficiency at Mach 0.8 was the value used in projecting the large fuel efficiency and operating cost advantages of an advanced turboprop over an equivalent technology turbofan powered aircraft. The $45^{\circ}$ swept propeller at this speed had an efificiency of 78.7 percent which was close to this study level.

By operating the 8 -bladed $45^{\circ}$ swept propeller at off design lower power loadings, higher efficiencies can be obtained at Mach 0.8 . This is shown in figure 9 where net efficiency is plotted against advance ratio for several levels of power loading. The typical variation of efficiency with advance ratio at a constant power loading (i.e., constant $c_{p} / j^{3}$ ) is a peaked curve. The reduction from the peak with increasing advance ratio is due to (1) a combination of lower ideal efficiencies due to increased swirl and tip losses and (2) lower blade sectional lift to drag ratios (from increasing local angles of attack). The fall-off with decreasing advance ratio is due to increased compressibility losses associated with the higher tip rotational speeds and/or again lower blade section lift to drag ratios (from decreasing local angles of attack). The circle symbol in figure 9 represents the 8-bladed $45^{\circ}$ swept propeller design point. The square symbol on the 80 percent power loading curve shows the design power loading and advance ratio of the 10-bladed $40^{\circ}$ swept propeller $(S R-6)$. The effect of operating the 8-bladed $45^{\circ}$ swept propeller at this reduced power loading and increased advance ratio ( 3.06 to 3.5 ) was to increase efficiency about 0.3 percent. This reduced power loading would result in a 12 percent larger propeller gianeter in an actual aircraft installation where power requirements are fixed. At 80 percent power loading and 3.3 advance ratio an efficiency of 79.7 percent was obtained and at 70 percent power loading efficiencies slightly above 80 percent were obtained.

A comparison of the 8- and 10-bladed propellers (ref. 12) is shown in figure 10 where net efficiency is plotted versus Mach number. These data sliow botn propellers operating at the 10-bladed propeller design power coefficient and advance ratio. The performance of the 10-bladed propeller was about $3 / 4$ to 1 percent higher than that of the 8-bladed model from Mach 0.6 to wach 0.75 . This higher performance was probably aue to the 1 percent higher induced (or ideal) efficiency predicted for the 10-bladed propeller. For the 8-bladed propeller the performance loss due to compressibility effects began near Mach 0.7 and increased gradually with increasing speed. The 10-bladed propeller showed no performance loss up to speeds of Mach 0.75 . Beyond this speed the efficiency fell rapidly with increasing Mach number and was about $1 / 2$ percent below the 8 -bladed model at Mach 0.8 .

Since the rapid performance loss of the $10-\mathrm{bladed}, 40^{\circ}$ swept propeller was believed to be due to che onset of choking in the interblade region near the hub, flow visualization studies were initiated to determine the extent of the interblade choking. Prior to testing, the propeller blades were painted with a red undercoat and a white overcoat. With the propeller operating at the desired conditions, an upstream jet atomizer was turned on to procuce a cloud of Di Octyl Phthalate (DOP) particles. Since UUP is an excellent solvent, the airflow directed cloud differentially removed the white overcoat paint layer to reveal the red undercoat and indicate the blade surface airflow patterns. The results of these "paint flow" visualization studies with the propeller operating near design at Mach 0.8 is shown in figure 11 . Although centrifugal as well as aerodynamic effects are evident, the photographs 
indicate a rather extensive shock on both the pressure and suction sides of the propeller blade, Surprisingly, the shock structure extends far from the hub region to near the blade mid radius. This would tend to indicate that the near hub chokjng was quite severe and propagated ics effects outward over a considerable portion of the blade span. The hub region of the 10-bladed SR-6 propeller presented a difficult design problem because of the low hub to tip ratio and the close blade spacing. Both of these factors would tend to reduce the interblade flow area and increase the likelihood of choking. In addition, the larger diameter of this propeller increased the blade root chord and structural constraints worked against reducing the root thickness to chord ratio to provide a larger flow area. Future efforts in spiniser area ruling techniques (ref. 7) to reduce the interblade root Mach number in combination with advanced controlled diffusion cascades, and the use of lighter, structurally superior, advanced composite blade material to achieve thinner root sections may be able to minimize these root section design problems. Advanced aerodynamic analys is methods for predicting high-speed propeller performance are being developed as a part of the NASA Propeller Research Program (ref. 7). The analysis methods (fig. 12) range from simple short runiling lifting line programs such as the existing strip analysis based upon Goldstein's work (ref. 13) to very complex long running programs such as the lifting surface analysis that solves the five Euler equations (ref. 14).

The existing Goldstein type strip analysis assumes the vortex wake is composed of a rigid helical vortex sheet, corresponding to the optimum spanm wise loading of a lightly loaded propeller. The propeller is restricited to havilig straight blades and there is no provision for a nacelle since the vortex wake extends to the axis. Simpie modifications have been made to existing analyses in an attempt to circumvent these restrictions. For exampie, the simple cosine rule is used for a swept blade and a radial gradient of axial velocity is used to approximate the effect of the nacelle.

More recent lifting line analyses, such as the curved lifting line program (ref. 15) and the propeller nacelle interaction program (ref. 16) include a swept lifting line capability and to varying degrees the ability to account for the presence of the nacelle in the analysis.

The curved lifting line analys is represents the wake by a finite number of helical vortex filaments instead of the continuous sheet of vorticity used by Goldstein. Each filament has a constant pitch but its location relative to the other filaments is arbitrary. The strengths of the individual wake filaments are related to the spanwise variations of the bound vortex strength. Since both of these are unknown the blade and wake vortex strengths are solved simultaneously. This is done by placing the bound vortex along the quarter chord line and solving for the vortex strengths which cause the flow to be tangent to the blade mean camber line along the threequarter chord line. The lift coefficient of the blade at any radial location is then determined from the bound vortex strength at the same radius. Drag is provided by correlated two-dimensional airfoil data. The total induced velocity is obtained by summing the induced flow calculated for each filament.

This analysis is currentiy restricted to single rotation propellers. The blades are represented by curved lifting lines which can have any arbitrary shape. The nacelle shape is restricted to an infillite cylinder because the wake rigid helical filaments cannot contract in the radial direction. The radially varying propeller inflow velocity due to nacelle curvature can be prescribed and taken into account in the analysis.

The propeller nacelle interaction analysis (ref. 16) also represents the wake by a finite number of vortex filaments. However, this analys is allows 
the vortex filaments to be placed along stream surfaces so that they conform to the shape of an axisymmetric nacelle. This is accomplished in the analysis by the calculation of the inviscid flow around the nacelle alone, which locates the wake vortex filaments around the nacelle and determines the radial variation of the inflow velocity at the propeller. The induced velocity is determine by summing the induced flow from the individual filaments and the swept lifting line. The local blade lift and drag are determined from from two-dimensional airfoil and cascade data contained in the program and the calculated local blade angle of attack. An optional step in the analysis allows the calculated blade forces to be used in a circumferentially averaged (axisynmetric) viscous compressible flow calculation to determine interblade and off-body velocities. This calculation can indicate whether the velocities are high enough to result in large shock wave losses, and can determine the drag of the nacelle in the presence of the propeller. The wake model in this analysis can be applied to both single and coaxial counter rotation propellers. The propellers can have blades of any arbitrary shape and the nacelle can be any axisymmetric geometry.

Lifting surface analyses that can solve the complete three-dimensional flow field are also under development. These analyses require the generation of a complex grid which conforms to the shape of the nacelle and propeller. The nacelle shape is required to be axisymmetric so that the flow between each two adjacent blades is the same, and it is only necessary to solve for the flow between two blades. Beyond the tips and upstream and downstream of the blades the flow is assumed to be periodic. On all solid surfaces the flow is required to be tangent to the surface.

The equations used in the Euler analysis are the five unsteady threedimensional Euler equations. These govern the inviscid flow of a compressible fluid and can accurately represent the total pressure variation caused by shock waves and the work done by the propeller. This analysis requires no wake modeling and no two-dimensional airfoil data. Another lifting surface analysis that is under devalopment solves the single full transonic potential equation and has a significantly shorter running time than the Euler analysis. It requires the wake location to be defined and does not account for shock total pressure variation although it indicates the shock location. once fully developed, bnth of the lifting surface analyses will be able to predict detailed pressure distributions on both sides of the propeller blade as well as the flow conditions in any portion of the off-body flow field. Such detailed three-dimensional results will be important tools for improving the aerodynamic, acoustic and structural performance of propellers through a becter understanding of the complicated flow processes of advanced high-speed ipropellers.

Although the curved lifting line ano the propeller nacelle interaction programs are still under development, comparisons of their results with experimental data obtained from the 8-bladed $45^{\circ}$ swept propeller (SR-3) have been made (ref. 17). These comparisons are shown in figure 13 and are intended to indicate the current status in the development of the prograns and demonstrate areas where the programs need to be improved. The versions of the programs used in the comparison were chosen to be as consistent as possible with each other. These versions include the effects of blade drag and camber, and a radially varying inflow into the propeller. In addition, the change in blade twist resulting from the centrigufal forces generated by blade rotation was determined from a finite element structural analysis at a rotational speed corresponding to the propeller design point advance ratio of 3.06 and free-stream Mach number of 0.8 . The resulting twist change of about 
2 degrees was used in each analysis when compared to the experimental design point data. For other rotational speeds the change in twist was assumed to be proportional to the rotational speed squared.

A comparioon of the experimental and analytical SR-3 propeller results is presented in figure $13(a)$ over a range of advance ratios. Both analytical methods overpredict the power coeffictent although the curved lifting line analysis more accurately predicts the level. Both methods deviate further from the data at both high and low ad ance ratios and are most accurate in the midrange. The assumed variation of twist change with rotational speed affects the shape of the power coeffictent curve. The assumed variation with rotational speed squared may be responsible for some of the discrepancy in the predicted and measured power coefficient results. For the efficiency, the curved lifting line analysis adequately ayrees with the data while the propeller nacelle interaction analys is considerably underpredicts the efficiency at low advance ratios and considerably overpredicts the efficiency at high advance ratios. The differences between the results from the two methods appear to be primarily due to the different approaches used for obtaining lift.

Comparisons for radial distribution of loading are shown in figure 13(b) for the SR-3 propeller at a free-stream Mach number of 0.8 and an ad:ance ratio of 3,06 . The propeller nacelle interaction analys is accurately predicts the loading distribution over most of the blade, deviating appreciably only in the outer 20 percent of the blade. The curved lifting line analysis overpredicts the loading inboard and underpredicts outboard, both by appreciable amounts. Since the experimental radial loading distribution was obtained from a probe located some distance downstream of the própelle re any blade wake rollup would cause the measured loading distribution in the wake to be different from the actual loading distribution on the blade. Also, changes in the flow streamlines from the propeller to the probe, caused by changes ill the nacelle diameter, would cause the loading distributions to be somewhat different at the two axial locations. Because of these uncertainties in the data it is not possible to conclude which method more accurately predicts the loading distribution.

Although the comparisons of figure 13 demonstrate the potential validity of the analytical results, they also indicate the need for additional refineinents in the analyses. The propeller nacelle interaction analysis, for example, contains additional features that were not used in the comparisons of figure 13 which are applicable to high-speed propellers. Some of these are distorted wake effects including tip rollup, wake compressibility effects through limited regions of influence, supersonic tip corrections to isolated airfoil data, and cascade data for the high solidity portions of the blades. Additional studies are required to determined wh:ch of these are appropriate for the prediction of high-speed propeller performance.

To improve the understanding of propeller design and to verify the emerging propeller analysis programs, a need exists for experimental information on the complicated flow field about the advanced high-speed propeller and nacelle. To fill this need a laser velocimeter (LV) system has been developed and used to obtain non-intrusive measurements of detailed velocities ahead of, in between, and behind propeller blades (refs. 18 and 19). A photograph of the system installed in the Lewis 8-by 6-foot wind tunnel is shown in figure 14. The laser velocimeter uses an argon ion laser and a 2-color 4- beam optics system to allow simultaneous measurements of two components of velocity. The rotational nature of the propeller-nacelle flow field permits 
two separate two dimensional measurements to be combined into 3adimensional velocity components.

Figure 15 presents some recent data obtained witl une laser velocineter at Mach 0.8 with the $8-$ bladed $45^{\circ}$ swept propeller (S $\$-3$ ) operating at its design point. Flow surveys made at two axial locations forward of the prom peller blades are shown at the left of the figure. Both surveys extended upwar from the spinner surface in the vertical piane above the spininer centerline to a location near the propeller tip radius. For these surveys, the laser velocimeter optical system was aligned to measure velocity only in the varticalllongitudinal plane. The Mach number shown in the figure at each radial station was obtained by circumferentially averaginy many measurements. Each data point in the survey represents about 1 uou separate data samples. The surveys are comparea in figure 15 to the flow field as calculated by an inviscid, axisyimetric, potential flow theory for the axisymmetric spinner/nacelle without the propeller blades. At the most forward survey location, the data and theory agreed very well indicating little influence of the operating propeller. The agreement was also good at the larger radial distances for the survey nearest the propeller leading edge, but at radial stations near the hub the LV data and the axisymmetric theory disagreed. Whereas the theory predicted a slight flow acceleration into the hub as a consequence of the local surface turning, the LV data indicated a significant flow retardation. Since the propeller biades near the hub are relatively thick and close together, this ret:idation is probably due to blade blockage. The right side of figure 15 posents the circumferential variation of axial velocity that was measured downstream of the propeller at four radial locations. Each plot extends 45 degrees in circumfarence or one blade spacing and represents a compllation of about 1000 separate data samples that were obtained behind the rotating propelier. These data were segregated into groups representing 30 angular segment positions relative to each blade pusition and then folded over to vield an average blade to blade profile. The general angular position of each plot is shown by the vertical line which represents the approximate circunferential position of the blade wake. The velocity profiles are characterized by a velocity jump across the blade wake. This results from the difference in velocity on the suction and pressure surfaces within the propeller. At radial locations near the tip of the blade the wake itself was very narrow and cannot be seen in the data of the two most outboard velocity surveys. But at radial locations nearer hub the laser velocimeter measured a definite blade wake as shown by the velocity defect in the two inner velocity survey plots. There is a large viscous wake and a rather large amount of scatter in the velocity survey data shown for the radial location nearest to the hub. Analysis of the data within each blade passage at this huo location has shown that this scatter arises from ilade to blade inconsistency and may be due to unsteady flow. It is believed that this poor flow quality results from the effects of the near hub flow blockage that was previously indicated by the flow survey ahead of the blades. Future laser velocimeter data are needed to examine the near hub flow region in more detail since unsteady flow in this region would affect any core inlet design.

\section{PROPELLER AEROLLASTIC RESEARCH}

The unconventional characteristics of advanced righ-speed propellers (fig. 16) have caused uncertainty regarding their aeroelastic behavior. Because of these uncertainties there is a need to establish an aeroelastic data 
base for these propellers. The aata base would enable the adequacy of existing aeroelastic prediction methods to be evaluated and improved where necessary, and would indicate where new analys is methods nead to be developed for analyzing advanced propeller designs.

Aeroelastic rescar. is in progress at Lewis using three of the highspeed propeller models; the 8 -bladed unswept and $45^{\circ}$ swept models, and the 10-bladed $60^{\circ}$ swept model (f1g.7). These models were designed to have the same aeroacoustic characteristics and geometry as fulleseale designs. They were not aeroelastically scaled models. However, the experimental aeroelastic data that were obtained from these modeis can be used to help evaluate the adequacy of the current prediction methods. The experimental research underway using these models includes work on forced excitation, stall flutter, and classical flutter (fig. 17). The status of the test program is shown in fig.ure 18. The ti.sting to determine the flutter characteristics of the three propeller models has been completed in the Mach 0 to 0.4 lower speed range and in the Maril 0.6 to 0.85 higher speed range. The isolated forced excitas tion tests, covering tne complete propeller speed range, have also been completed. Installed forced excitation tests at the NASA Ames Research Center have been completed for the 8-bladed unswept propeller model (SR-2) and are planned for the 8-bladed $45^{\circ}$ swept model (SR-3).

The data for all of the aeroelastic tests were obtained by operating each propeller at various blade angles and rotational speeds at each Mach number and recording the output of strain gauges that were installed on selected blades. In addition, the forced excitation tests included angle of attack as an additional variable to obtain blade dynamic response at angled inflow conditions. Since the data analys is from these tests is still in progress, only a brief qualitative summary of the test results is avallable at this time. During the low-speed tests, stall flutter was found at about a $32^{\circ}$ blade angle with the 8-bladed unswept model (SR-2). The 8-bladed $45^{\circ}$ swept model (SR-3) arid the 10-uladed $60^{\circ}$ swept model (SR-5) did not exhibit stall flutter but did encounter large amplitude aeroelastic instabilities at much lower blade angles $\left(-4^{\circ}\right.$ and $+4^{\circ}$, respectively). Preliminary analys is indicates that these may have been a wake chopping phenomena (ref. 20). Results of the isolated forced excitation tests at low speed generally show that the $60^{\circ}$ swept model (Sk-5) had a significantly larger operating envelope than the other models before stresses due to stalled flow or dynamic response at angled inflow conditions limited operations. This trend was also shown by the $45^{\circ}$ swept model (SR-3) in that it had a larger operating envelope than the unswept model $(S R-2)$. These findings indicate that blade sweep has a favorable effect on low-speed aeroelastic characteristics. The high-speed isolated forced excitation test results are not yet analyzed and the effect of sweep is undetermined. However, the high-speed flutter results discussed in the following paragraphs indicate that sweep is aeroelasticaliy detrimental at high speeds.

During the high-speed flutter tests a classical coupled bending-torsion flutter phenomena was encountered with the $10-\mathrm{bladed} 60^{\circ}$ swept propeller model $(S R-5)$. The other two propelier models experienced no flutter. The SR-b flutter condition occurred at free-stream Mach numbors of 0.6 and greater. The flutter boundary, in terins of blade angles and Mach number is shown in i igure 19. Analysis of these data indicate that the flutter occurred when the blade helical tip Mach number reached a value of about 0.95 and was generally independent of propeller rotational speed, blade angle, or power load.ing. The flutter testing on this propeller was expanded to include 2- and $5-\mathrm{bladed}$ configurations and the results are summarized in figure 20. The flutter speed, in terms of helical tip Mach number, decreased as the number 
of blades was increased. This result indicates that eassade effects have a strong influence on the flutter boundary and that cascade aerodynamics need to be incorporated in elassical tlutter prediction sodes.

The analytical effort that is underway at Lewis also includes work on stall flutter, classical flutter, and forced excitations. This effort is being influenced by the experimental work that has been done and shows that modifications to existing analytical methods are required in order to accu. rately predict the aeroelastic characteristics of these advanced high-speed propellers. The elassical flutter of the SR-S propeller, for example, has shown that cascade effects must be included in the analys is codes. These effects can be accounted for by using Smith's unsteady aerodynamic theory (ref. 21) in subsonic flow, and Adamezyk and Goldstein's theory (ref. 22) in supersonic flow. In addition, references 23 and 2,4 , and the preiminary analysis of the high-speed propeller data indieate that sweep has a detrimental effect on elassical flutter and must also be included in acroelastic predicm tion codes. Although the theories of references 21 and 22 were developed for unswept blades, they can be modified to account for sweep by applying similarity laws for ronrotating wings as was done in references 23 and 24 . Several unpublished inhouse and colltractor analys is codes have incorporated these effects and have given results that are in good agreement with the experimental SR-5 propeller classical flutter results.

Single data points from the high-speed forced excitation tests were picked to be compared with theoretical predictions. These preliminary resuits are presented in figure 21 in terms of blade sweep, and compare the one-p stress levels measured on the most inboard strain gauge of each propeller model to the predicted values. The prodiction agrees well with the data for the straight bladed propeller but shows only reasonable agreement with the swerit propeller data and tends to underpredict their measured stress levels. Tiq aredicted stress levels used in figure 21 were calculated by a Lewis con- rasis: method. This method uses a steady-state lifting-line analys is to compuce al: loads at various blade azimuthal positions in combination with a firite element structural code to predict the stress levels. Efforts are continuing the improve the prediction capability of this method and other analytical approaches.

Near-terin future efforts in aeroelastics will focus on completing the ana,ysis of the experimental data that have already been obtained and comparing them with analysis code results. These efforts will identify areas where the codes need improving. Future axperimental work is also planned. This includes a model of the 8 -bladed $45^{\circ}$ swept propeller fabricated from composite materials (SR-3C) and a new higil-speed propeller model that is aeroelastically scaled $(S R-7)$.

\section{PROPELLER ACOUSTIC RESEARCH}

In order for an advanced turboprop aircraft to be competitive with an advanced turbofan aircraft, the turboprop fuselage interior should be equivalent in comfort (low levels of noise and vibration) to that of the turbofan aircraft. A quiet fuselage interior will be more difficult to achieve in the turboprop aircraft. This is because its fuselage may be in the direct noise tield of the propeller whereas the inlet duct of a turbufan shielus the fuselag. from tan noise. In addition, the propeller tip vortex from a wing mounted tractor propeller induces significant wing surface pressure fluctuations that could be transinitted as structural borne noise to the fuselage interior (ref. 25). This area needs further investigation. Advanced tech- 
nologies are currently being evaluated to reducing propeller source noise and improving fuselage wall noise attenuation. Fuselage wall study results have shown improved wall attenuation potential with reduced weight penalty by using a double wall fuselage construction and lighter composite materials (refs. 26 and 27). Reduced propeller source noise is being studied with propeller sweep and new acoustic analysis techniques.

Acoustic measurements have been made in the Lewis 8- by 6-foot wind tunnel on the high-speed turboprop models. The noise data were obtained from pressure transducers located on the side-wall and celling of the tunnel. Acoustic results from tests of the $S R-2, S R-1 M$, and $S R-3$ eight-bladed prope1lers are reported in references 2 and 3 . Additional noise data on the SR-3 is reported in reference 28. There were some initial concerns about the quality of the noise data obtained in this tunnel. It was felt that the tunnel background noise, primarily generated by the turnel drive compressor, and the tunnel wall reflections might mask or distort the acoustic measurements. These areas of concern were investigated and reported in references 2 and 3 . For most of the propeller acoust: c test conditions it was found that the propeller tones were distinguishable from and above the tunnel background noise. Also, the effects of tunnel wall reflections were not as severe as at first feared. Although the data of references 2 and 3 did not prove that the measured propeller noise was free of reflection errors, they did show a fall off of noise with distance and a directivity that indicated that the direct-incidence noise signals were not everywhere dominated by tunnel reflections. These results indicated that a relative comparison of noise levels measured in the tunnel for the various, high-speed propellers would be valid. In addition, some recent flight noise tests using the SR-3 propeller mounted above the fuselage of a Jetstar afrcraft have been made and the results have been compared to the SR-3 wind tunnel data (refs. 29 and 30). These comparisons showed good agreenent and indicated that the 8-by-6 foot wind tunnel is a viable location for obtaining absolute levels of peak noise and can also yield meaningful directivity data for the high-speed propellers.

The effects of $b$ iade sweep on the wave shapes of the measured near-field pressure generated by 8-bladed propellers are shown in figure ?2. The propellers wers sperating in the tunnel near their design conditions. Shown are signal enhariced pressure-time traces for both the straight blade (SR-2) and the aero/acoustically designed $45^{\circ}$ swept blade $(S R-3)$. They were obtained from the transducer on the tunnel wall nearest to the propeller plane (one diameter from the blade tip). The straight blade propeller produced a high amplitude sieep wave shape which approached the classic $N$ wave shock pattern. However, the quieier $45^{\circ}$ swept blade produced an almost sinusiodal wave which was also of considerably less amplitude. These differences in the character of th? noise indicate that the aero/acoustically designed planform of the $45^{\circ}$ swept blade was succesful in reducing the sharp pressure rise that would normally be associated with supersonic helical tip speed propellers.

The magnitude of the noise reduction achieved with the $45^{\circ}$ swept propeller is more apparent in figure 23. The maximum blade passage tone measured on the tunnel ceiling is plotted against the helical tip (total, including tunnel and rotationa1) Mach number. The data were obtained at approximately the design power coefficient by holding the advance ratio constant. The he1ical tip Mach number was varied by changing tunnel and propeller rotational speed. In general, the noise of both the straight and $45^{\circ}$ swept blade increased rapidly as the helical tip speed approached Mach 1.0. At higher helical tip speeds the noise level was approximately constant. Over the complete test range, the noise level of the $45^{\circ}$ swept blade was consistently 
lower than that of the straight blade. At the design tip Mach number of 1.14 $i$ was 5 to $6 \mathrm{~dB}$ lower. At lower Mach numbers the noise reduction was slightiy larger (7 to $9 \mathrm{~dB}$ ).

Theoretical noise prediction models developed for high-speed propellers are based on linear acoustic theory, one of these theories (refs. 31, 32, and 33) was used to predict the noise of the 8-bladed $45^{\circ}$ swept propeller model (SR-3) and the results are reported in ref. 34. A comparison of this model with tunnel data is shown in figures 23, Generally good agreement is shown with the SR-3 model data at tip speeds up to around Mach 1.05. Above a helical tip Mach number of 1.05, the theory overpredicts the near-field noise with the amount of overprediction increasing with increasing Mach number. This linear theory does not predict the levelling off of the peak noise as shown by the data. This levelling off of propeller noise at supersonic helical tip Mach numbers was observed in older propeller tests (ref. 35). At these speeds, shock waves can propogate from a rotating propeller blade and cause non-linear acoustic sources. To address this oource, an initial shock wave noise model was formulated at the NASA Lewis Research Center (ref. 36). This model predicts the noise resulting from the shock pressure rise caused by the propeller tip alone. The shock pressure rise prediction for the 8bladed $45^{\circ}$ swept propeller is compared to the data in figure 23. Although the shock wave model predicts a rather substantial peak in the noise level not measured in the tunnel data, it also predicts the levelling-off trend in noise at the higher supersonic tip speeds that agrees with the trend in the tunnel data. The magnitude of the shock wave model prediction is too high. This may be due to the fact that the $45^{\circ}$ swept propeller was designed to achieve sonle nóise cancellation between the inboard and outboard regions of the blades and only the shock structure from the tip region was modelled. Reference 36 reports much better agreement between data and the shock wave model for propellers that were not designed to achieve noise cancellation. The levelling off trend from the shock wave model at supersonic helical tip speeds indicates that this approach may be a viable method to pursue for enhancing the future acoustic modelling of high-speed propellers.

Past attempts at reducing turboprop fuselage interior noise levels by modifications to the fuselage sidewall have met with limited success. These attempts have assumed that the fuselage interior noise levels are governed by the transmission of directly radiated propeller noise through the fuselage sidewall. The limited success of acoustic sidewall treatment methods suggest that other noise paths to the fuselage may be significant or even dominant. For example, a wing surface downstream of the propeller is exposed to the rotating unsteady propwish and could experience significant surface pressure fluctuations. Such propeller induced excitations inight be transmitted via wing structural paths to the fuselage structure, to be radiated as noise or transinitted through the cabin as undesirable vibration.

To assist in evaluating this hypothesis, tests were conducted in the Lewis 8- by 6-foot wind tunnel to evaluate the propeller slipstream of the 8-bladed $45^{\circ}$ swept propeller. Results are presented in reference 25 and are summarized in figure 24. Pressure transducers were flush mounted in the tunnel ceiling near the plane of the propeller about 1.5 propeller diameters from the blade tip. Additional transducers were flush mounted on opposite surfaces of a small airfoil shaped wake survey probe located one diameter downstream of the propeller. The probe was mounted on a traversing mechanism and the data of figure 24 were obtained at a propeller radius location where the tip vortex could be intercepted. This was shown to be the radius where the maximum dynamic pressure fluctuations occurred. The probe was set at an 
incidence angle of 6 degrees so as to be approximately aligned with the expected propeller slipstream swirl angle.

A comparison of the maxtmum sound pressure level spectra measured on the tunnel celling with that obtained by placing the wake survey transclucer in the tip vortex is shown in figure 24 for the propeller operating at its design power coefficient and advance ratio at a tunnel Mach number of 0.6 . The ceiling and wake survey data were obtained at different times to avoid possible probe acoustic interference effects on the celling measurements. At the propeller blade passing frequency of approximately $100 \mathrm{~Hz}$ the sound pressure level measured on the wake probe surface due to the action of the tip vortex is about 15 dB higher than the maximum propeller noise measured on the wind tunnel celling. The tip vortex spectra is rich in higher harmonics showing aven larger increases in sound pressure level compared to the gelling transducer. This suggests that the tip vortex is highly compact and subjects the wake probe surface to a sharp "slap" - or nearly impulsive excitation - as opposed to a more sinusoidal excitation at the blade passing frequency. Somewhat similar results were obtained at Mach 0.8 although the higher harmonics in the tip vortex vere usually significantly below the level of the fundamental.

These results indicate that a propeller tip vortex can subject a downstream wing or mounting structure to a much greater excitation than might be experienced by the aircraft fuselage sidewali exposed to directly radiated propeller noise. If fuselage and wing surfaces are equally responsive to the incident dynamic pressure, and transmit this response with equal efficiency to the fuselage interior, the interior noise levels may be dominated by the interaction of the propelier tip vortex with the wing or other portions of the airframe. Additional work is needed to determine wing surface response to propeller tip vortex induced excitations and the effectiveness of this response in radiating noise to the fuselage interior. In addition, with the high power loading (and small diameter) of these advanced propellers, it may be possible to acoustically treat a small region of the wing to minimize any structural transmission of this noise io the fuselage.

\section{FUTURE POTENTIAL.}

The performance results achieved with the high-speed propeller models show that future advanced turboprop powered aircraft may be potentially far superior in performance to an equivalent turbofan powered aircraft. These wind tunnel results have shown propeller efficiencies near 80 percent at Mach 0.8 with near-field cruise noise reductions of about $6 \mathrm{~dB}$. Further efficiency improvements and noise reductions may be possible with some of the advanced experimental and analytical technology work that is underway or planned as part of NASA's high-speed propeller research program. Two future high-speed propeller models are currently being planned to address the speed range from Mach 0.7 to 0.8 . The latest refinements to the evolving advanced analysis methods in aerodynamics, acoustics, and aeroelastics will be used to assist in the design of these models.

Another approach which is being studied to further improve performance is to mecover the thrust loss in the swirl of the single-rotation propeller slipstream. Methods being considered for swirl recovery are wing contouring, stators behind the propeller, or a coaxial counter-rotation propeller (fig. 25). The magnitude of the swirl loss of the high power loading single-rotation propellers is shown in figure 26. At the cruise operating condition of Mach 0.8 and $10.668 \mathrm{~km}$ (35000 ft) altitude, the swirl loss 
ranges from about 7 to 11 percent for propeller tip speeds between 183 and 244 meters $k e r$ second $(600$ and $800 \mathrm{ft} / \mathrm{sec})$ at a power loading of $301 \mathrm{~kW} / \mathrm{m}^{2}$ $\left(37.5 \mathrm{hp} / \mathrm{ft}^{2}\right)$. A counter-rotation propeller has the potential for recover. ing most of this loss and may also reduce any blade-to-blade choking losses incurred in the inboard region of the 8 to 10 blade single-rotation propellers by providing a larger flow area between blades. In addition, the proplet blade tip devices shown in figure 25 have the potential of further improving performances by reducing tip losses (ref. 37). Counter rotation is currently being studied inhouse at Lewis and on contract at ilamilton Standard to evaluate the potential of this concept. In addition, planning and some limited analytical activity is underway to further investigate counter rotation. Initial efforts will include the comparison of analytical predictions, using the counter-rotation lifting line analysis of reference 7, with existing NACA data from the 1950's. Preliminary plans are also being prepared for an experinental counter-rotation model prograin. This includes establishing the requirements for a modern propeller test rig for investigating advanced counter-rotation propeller concepts.

SYMBOLS

$\begin{array}{ll}A & \text { noise amplitude } \\ C_{p} & \left.\text { power coefficient }=P / \rho_{0} n^{3}\right)^{5} \\ D & \text { blade tip diameter, cm (in.) } \\ d B & \text { decibel } \\ d C_{p} / d(r / R) & \text { elemental power coefficient } C_{p}=\int\left[d C_{p} / d(r / R)\right] d(r / R) \\ J & \text { advance ratio, } V_{0} / n D \\ M & \text { Mach number } \\ M_{h t} & \text { blade helical tip Mach number } \\ M_{l} & \text { local Mach number } \\ M_{0} & \text { free-stream Mach number } \\ n & \text { rotational speed, revolutions per second } \\ P & \text { power, kW (ft-lb/sec) } \\ R & \text { blade tip radius, cm (in.) } \\ r & \text { radius, cm (in.) } \\ S H P & \text { shaft power, kW (hp) } \\ V_{0} & \text { free-stream velocity, m/sec (ft } / \mathrm{sec}) \\ n & \text { rency }=\left(T \cdot V_{0}\right) P\end{array}$




\section{REFERENCES}

1. Jeracki, R. J., Mikkelson, D. C., and Blaha, B. J., "Wind Tunnel Perfornance of Four Energy Efficient Propellers Designed for Mach 0.8 Cruise," SAE Paper 790573, Apr. 1979. (NASA TM-79124.)

2. Dittmar, J. H., Blaha, B. J., and Jeracki, R. J., "Tone Noise of Three Supersonic Helical Tip Speed Propellers in a Wind Tunnel at 0.8 Mach Number," NASA TM-79046, 1978.

3. Dittmar, J. H., Jeracki, R. J., and Blaha, B. J., "Tone Noise of Three Supersonic Helical Tip Speed Propellers in a Wind Tunnel," NASA TM-79167, 1979.

4. Mikkelson, D. C., Blaha, B. J., Mitche11, G. A., and Wikete, J. E., "Design and Performance of Energy Efficient Propellers for Mach 0.8 Cruise," SAE Paper 770458, Mar. 1977. (NASA TM X-73612.)

5. Hanson, D. B., "Near Field Noise of High Tip Speed Propellers in Forward Flight," AIAA Paper 76-565, July 1976.

6. Metzger, F. B., and Rohrbach, C., "Aeroacoustic Design of the Prop-Fan," AIAA 79-0610, Mar. 1979.

7. Bober, L. J., and Mitche11, G. A., "Summary of Advanced Methods for Predicting High Speed Propeller Performance," AIAA Paper 80-0225, Jan. 1980.

8. Rohrbach, C., Metzger, F. B., Black, D. M., and Ladden, R. M., "Evaluation of Wind Tunnel Performance Testings of an Advanced $45^{\circ}$ Swept EightB laded Propeller at Mach Numbers from 0.45 to 0.85," NASA CR 3505, 1982.

9. Dugan, J. F., Jr., Gatzen, B. S., and Adamson, W. M., "Prop-Fan Propulsion - Its Status and Potential," SAE Paper 780995, Nov. 1978.

10. Swallow, R. J., and Aiello, R. A., "NASA Lewis 8- by 6-Foot Supersonic Wind Tunne1," NASA TM X-71542, 1974.

11. Mikkelson, D. C., and Mitcheli, G. A., "High Speed Turboprops for Executive Aircraft, Potential and Recent Test Results," NASA TM-81482, 1980.

12. Jeracki, R. J., and Mitchel1, G. A., "Low and High Speed Propellers for General Aviation - Performance Potential arid Recent Wind Tunnel Test Results," NASA TM-81745, 1981.

13. Goldstein, S., "On the Vortex Theory of Screw Propellers," Royal Society (London) Proceedings, Vol. 123, No. 792, Apr. 6, 1929, pp. 440-465.

14. Chaussee, D. S., Computation of Three-Dimensional Flow Through Prop Fans," Nielsen Engineering and Research, Inc., NEAR TR-199, June 1979.

15. Sullivan, J. P., "The Effect of Blade Sweep on Propeller Performance," AIAA Paper 77-716, June 1977.

16. Egolf, T. A., Anderson, 0. L., Edwards, D. E., and Landgrebe, A. J., "An Analys is for High Speed Propeiler-Nacelle Aerodynamic Performance Prediction; Volume 1, Theory and Initial Application and Volume 2, User's Manual for the Conputer Program," United Technologies Research Center, R7y_ 912949-19, June 1979.

17. Bober, L. T., and Chang, L. K., "Factors Influencing the Predicted Performance of Advanced Propeller Designs," NASA TM-82676, 1981.

18. Freedman, R. J., and Greissing, J. P., "The Development and Utilization of a Laser Velocimeter system for a Large Transonic Wind Tunnel," NASA TM $82886,1982$. 
19. Serafini, J. S., Sullivan, J. R., and Neumann, H. E., "Laser-Velocimeter Flow-field Measurements of an Advanced Turboprop," AIAA Paper 81-1568, July 1981.

20. Amatt, W., Bates, W. E., and Borst, H. V., "Summary of Propeller Design Procedures and Data, Volume II - Structural Analys is and Blade Design," USAAMRDL Technical Report 73-34B, Nov. 1973, p. 168.

21. Smith, S. N., "Descrete Frequency Sound Generation in Axial Flow Turbomachines," ARC RaM No. 3709, 1973.

22. Adamczyk, J. J., and Goldstein, M. E., "Unsteady Flow in Supersonic Cascade with Subsonic Leading Edge Radius," AIAA Journal, Vol, 16, No. 12, Dec. 1978, pp. 1248-1254.

23. Barmby, J. G., Cunningham, H. J., and Garrick, I. E., "Study of Effects of Sweep on the Flutter of Cantilever Wings," NACA TN-2121, 1950.

24. Bisplinghoff, R. L., Ashley, H., and Halfman, R. L., Aeroelasticity, Adison-Wesley Publishing Company, Inc., Cambridge, Mas sacliusetts, I956.

25. Miller, B. A., Dittmar, J. H., and Jeracki, R. J., "The Propeller Tip Vortex - A Possible Contributor to Aircraft Cabin Noise," NASA TM 81768 , 1981 .

26. Revell, J. D., Balena, F. J., and Koval, L. R., "Analytical Study of Interior Noise Control by Fuselage Design Techniques on High-Speed, Propeller-Driven Aircraft," Lockheed-Califorrija Company, Burbank, CA, LR-29382, Apr. 1980. (NASA CR-159222.)

27. Rennison, D. C., Wilby, J. F., and Marsh, A. H., "Interior Noise Control Prediction Stuay for High-Speed Propeller-Driven Aircraft," Bolt, Beranek and Netyman, Inc., Canoga park, CA, BBiN-4020, Sept. 1.9̈79. (NASA CR.-159200.)

28. Dittmar, J. H., and Jerscki, R. J., "Additional Noise Data on the SR-3 propeller," NASA TM 81736, 1981.

29. Dittilar, J. H., and Lasagna, P. L., "A Preliminary Comparison Between the SR-3 Propeller Noise in Flight and in a Wind Tunnel," NASA TM 82805, 1982.

30. Macka17, K. G., Lasagna, F. L., and Dittmar, "In-Fifight Acoustic Results from an Advanced Design Propelier at Mach Numbers Up to 0.8," AIAA Paper No. 82-1120, June 1982.

31. Farassat, F., "Theory of Noise Generation from Moving Bodies "with an Application to Helicopter Rotors," NASA TR R-451, 1975.

32. Farassat, F., "Discontinuities in Aerodynamics and Aeroacoustics - The Concept and Applications of Generalized Derivatives," Journal of Sound and Vibration, vol. 55, no. 2, Feb. 1977, pp. 165-193.

33. Farassat, F., Morris, C. E. K., and Nystrom, P. A., "A Comparison of Linear Acoustic Theory with Experimental Noise Data for a Small Scale Hovering Rotor," AIAA Paper 79-0608, Mar. 1979.

34. Dittmar, J. H., "A Comparison Between and Existing Propeller Noise Theory and Wind Tunnel Data," NASA TM-81519, 1980.

35. Hubbard, H. H., and Lassiter, L. W., "Sound From a Two-Blade Propeller at Supersonic Tip Speeds," NACA Rep.-1079, 1952.

36. Dittmar, J. H., and Rice, E. J., "A Shock Wave Approach to the Noise of Supersonic Propellers," NASA TM 82752, 1981.

37. Sullivan, J. P., Chang, L. K., and Miller, C. J., "The Effect of Proplets and Bi-Blades on the Performance and Noise of Propellers," SAE paper 810000 , Apr. 1981. 


\section{ORIGINAL PAGE \\ BLACK AND WHITE PHOTOGRAPH}

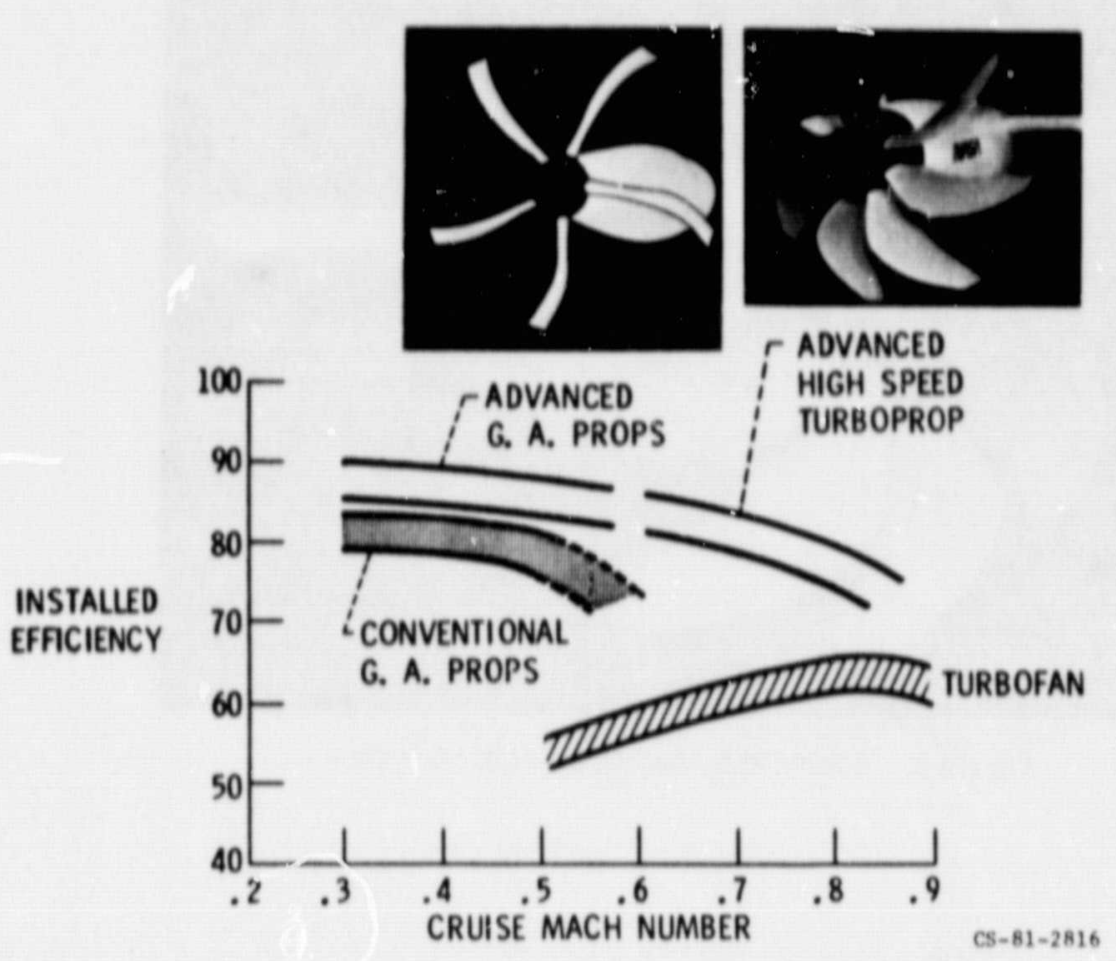

Figure 1. - Installed cruise efficiency trends.

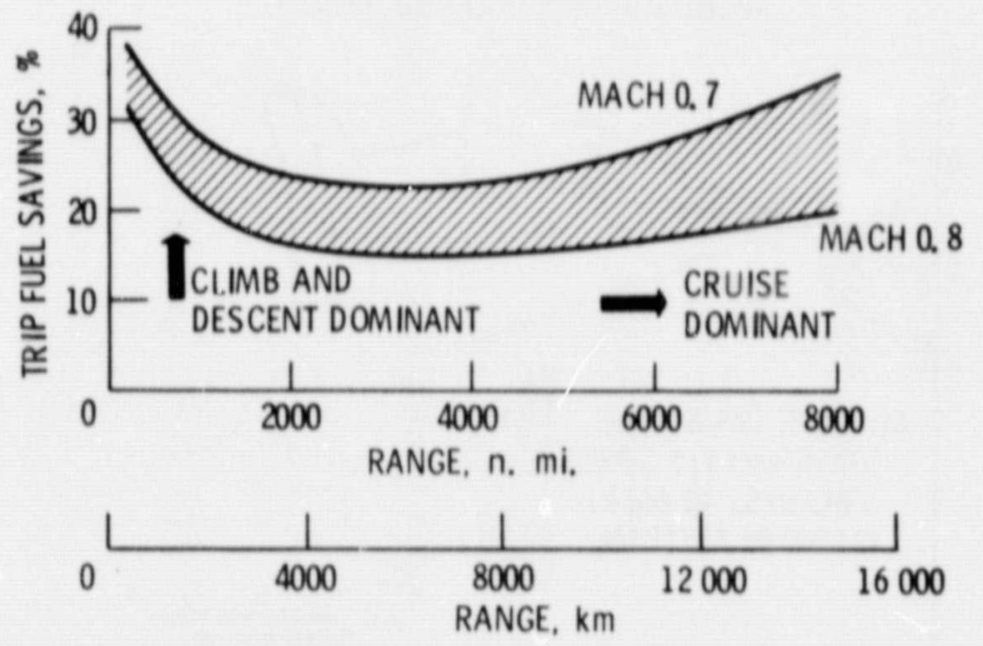

Figure 2. - Fuel savings trends of advanced turboprop aircraft over comparable turbofan aircraft. 


\section{ORIGINAL PAGE \\ BLACK AND WHITE PHOTOGRAPH}

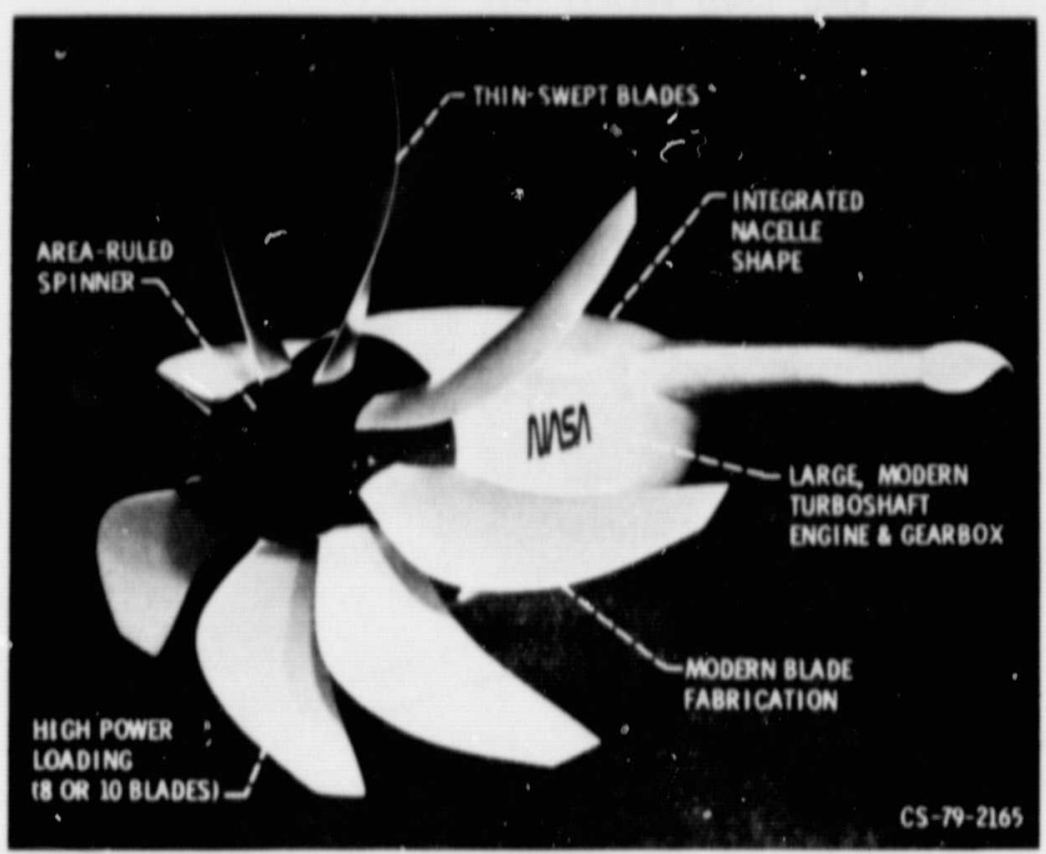

Figure 3. - Advanced turboprop propulsion system.

\section{CURVE}

A SECET!ON MACH NUMBER, NO VELOCITY

SUPPRESSION OR SWEEP

B DRAG DIVERGENCE MACH NUMBER (NACA 16-SERIES)

C SECTICN MACH NUMBER WITH $30^{\circ}$

TIP SWEEP

D EFFECTIVE SECTION MACH NUMBER (WITH SUPPRESSION AND SWEEP)

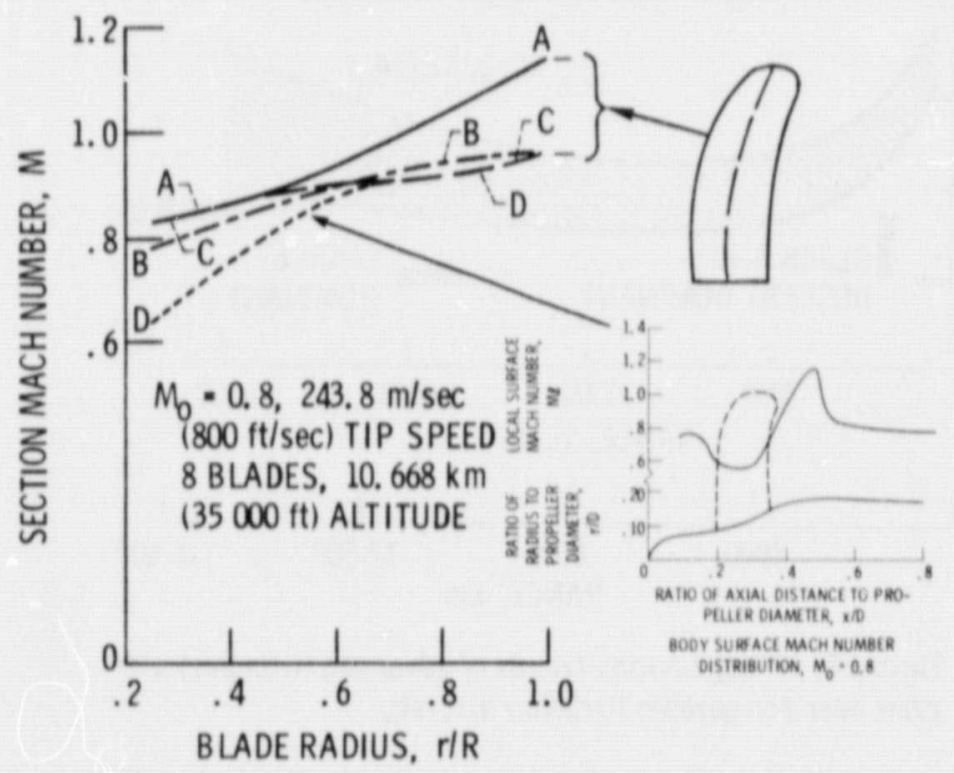

Figure 4. - Effects of advanced aerodynamic concepts on blade section Mach number distributions. 


\section{ORIGINAL PAGE IS \\ OF POOR QUALITY}
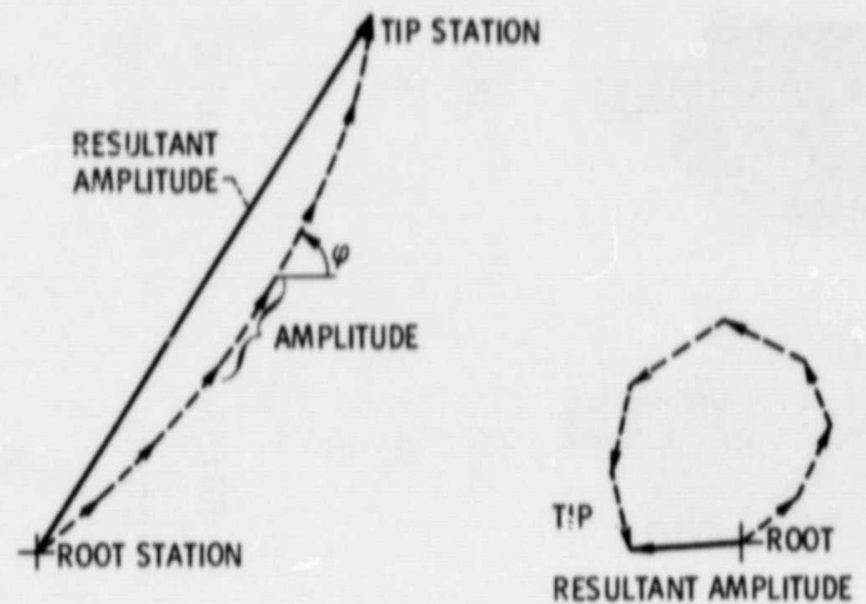

(a)

(b)

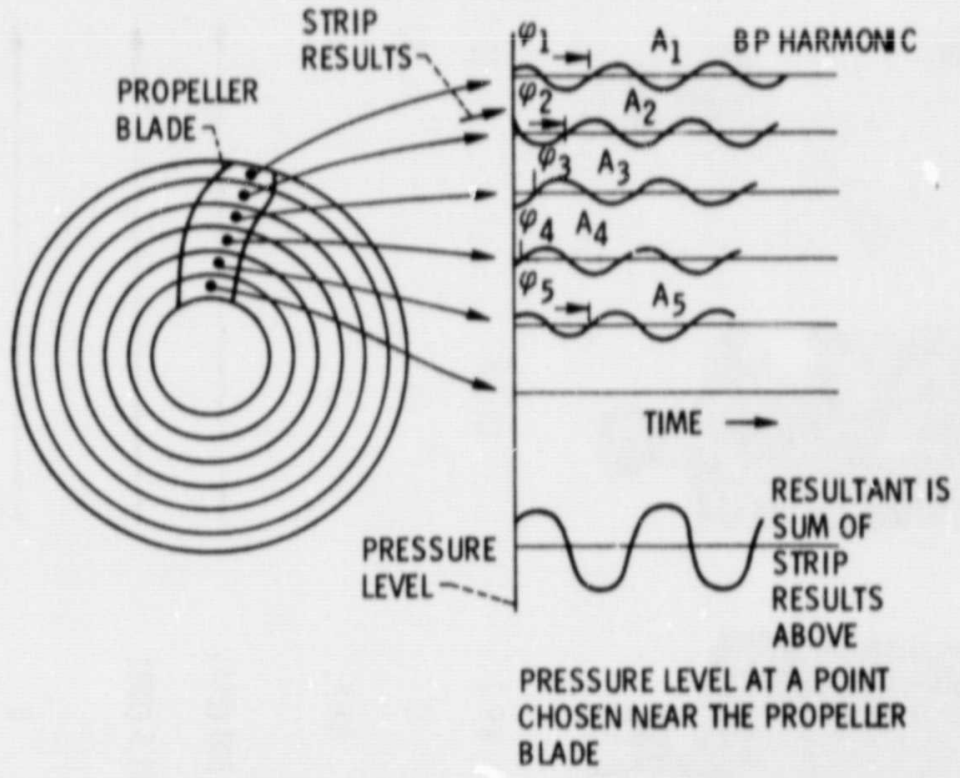

(a) Poor cancellation of unswept propeller.

(b) Strong cancellation of acoustically swept propeller.

Figure 5. - Acoustic strip analysis technique for near-field noise reduction. 


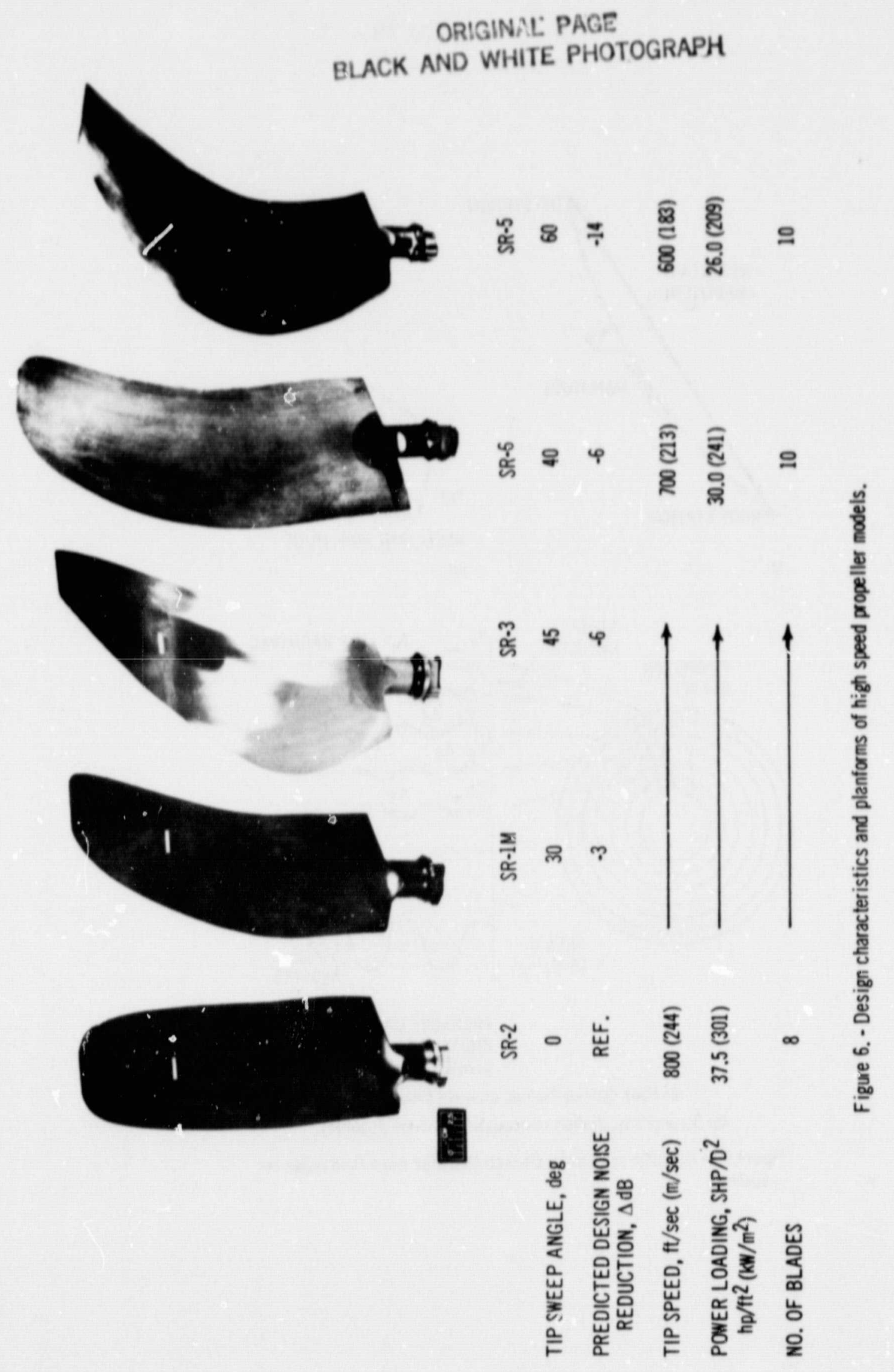



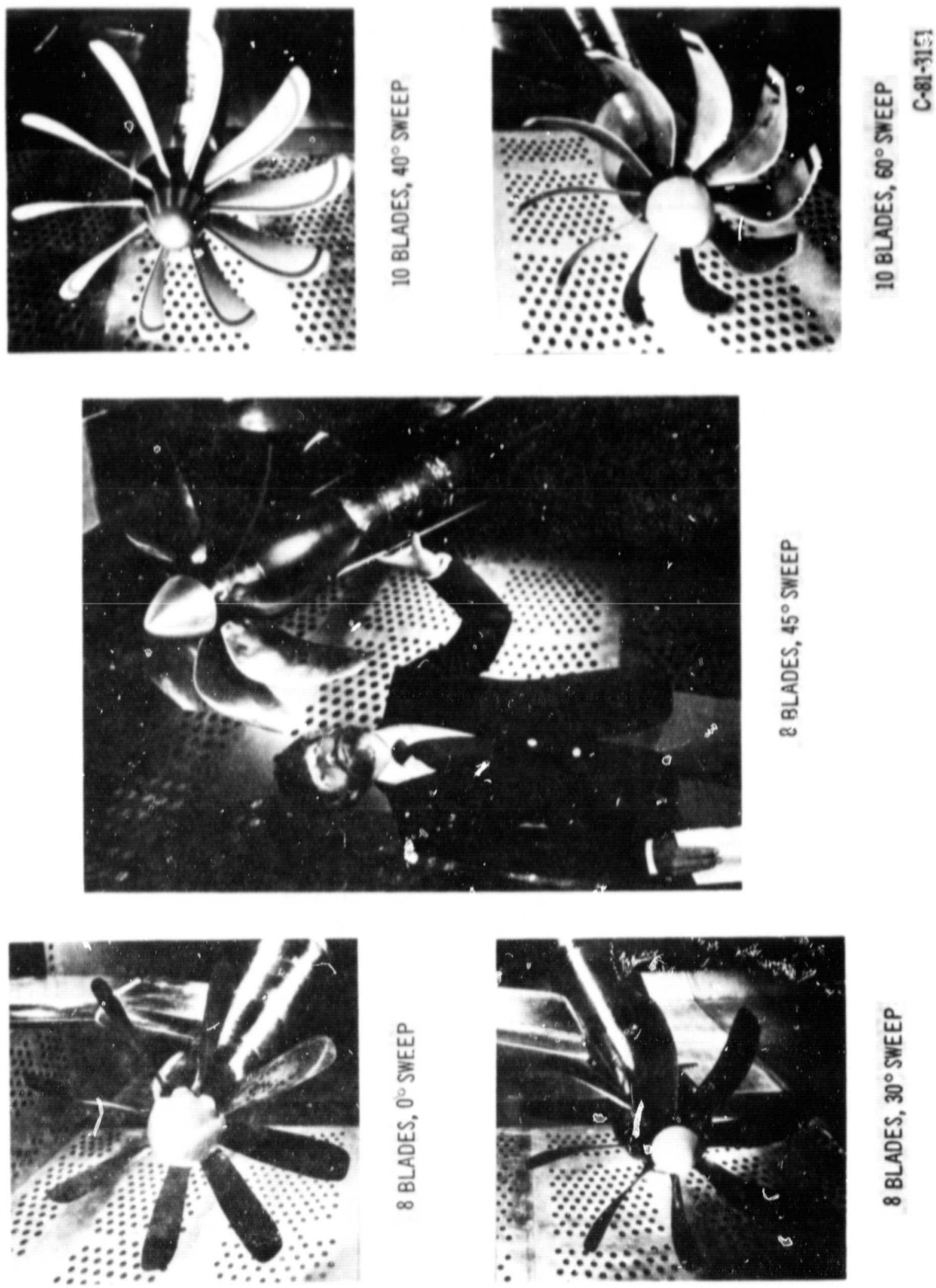

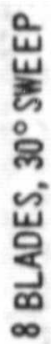




\section{ORIGINAL. PAGE IS \\ OF POOR QUALITY}

AREA RULED SPINNER, $J \cdot 3.0 i, c_{p} \cdot 1.7$

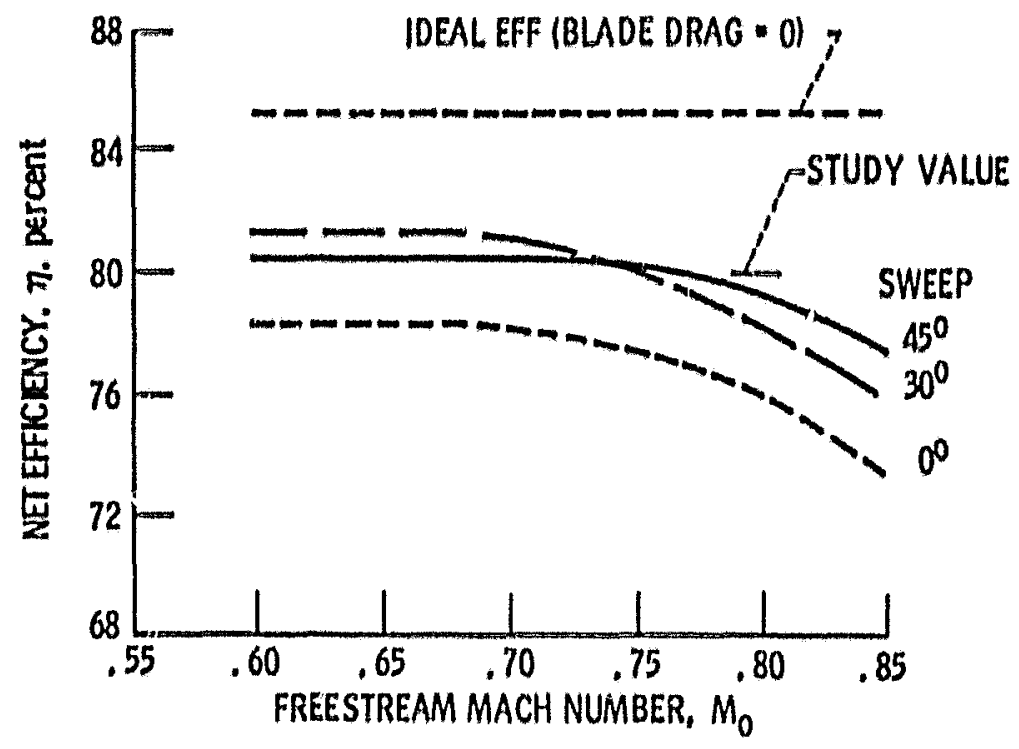

Figure 8. - Performance summary of 8-bladed propellars.

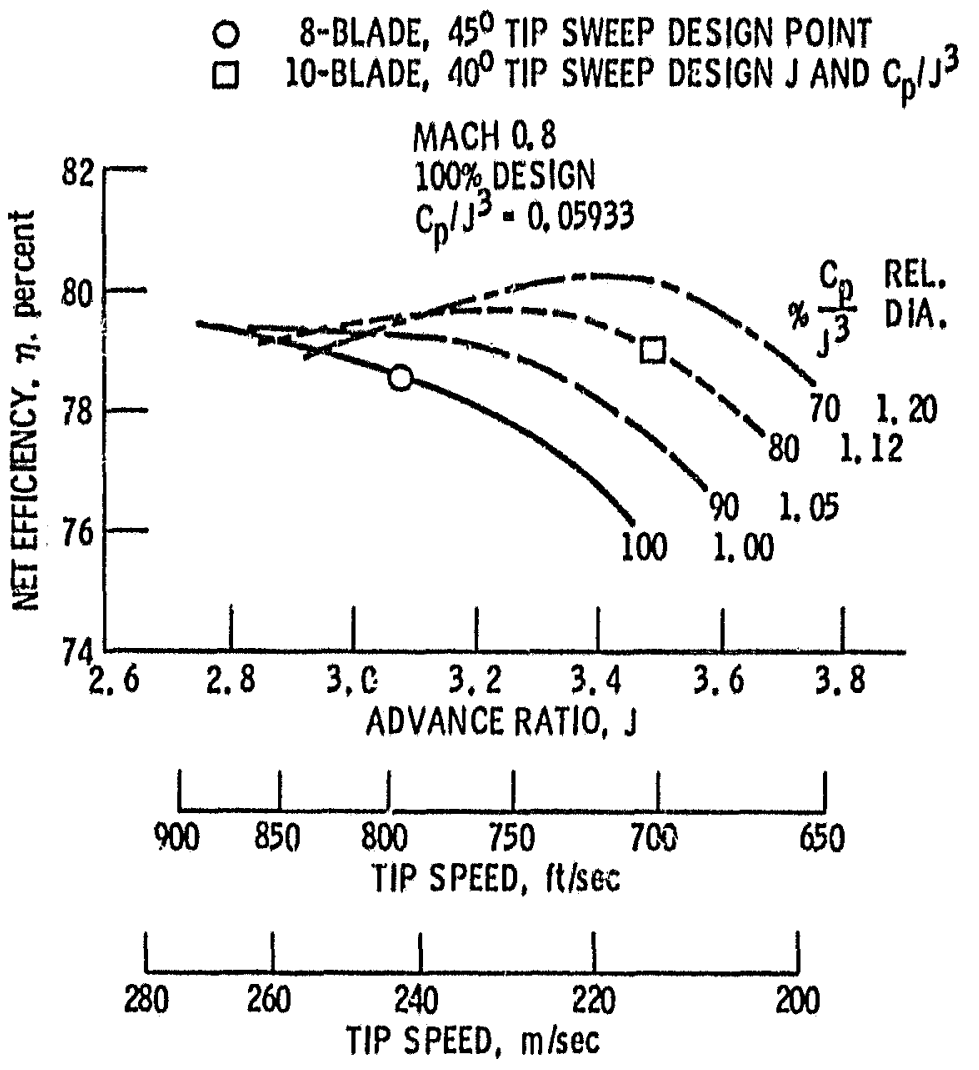

Figure 9. - Effect of power loading and advance ratlo on performance of the 8-bladed $45^{\circ}$ swept propeller (SR-3). 


\section{BLACK AND WHITE PHOTOGRAPH}

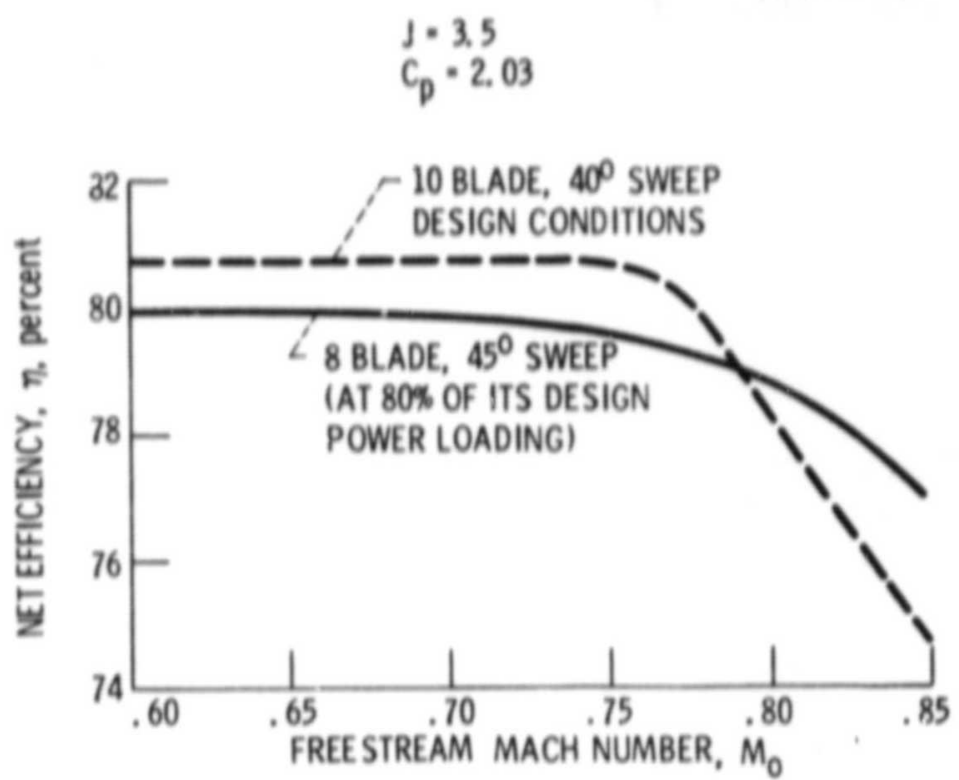

Figure 10, - Comparison of 8 and 10 blade performance.

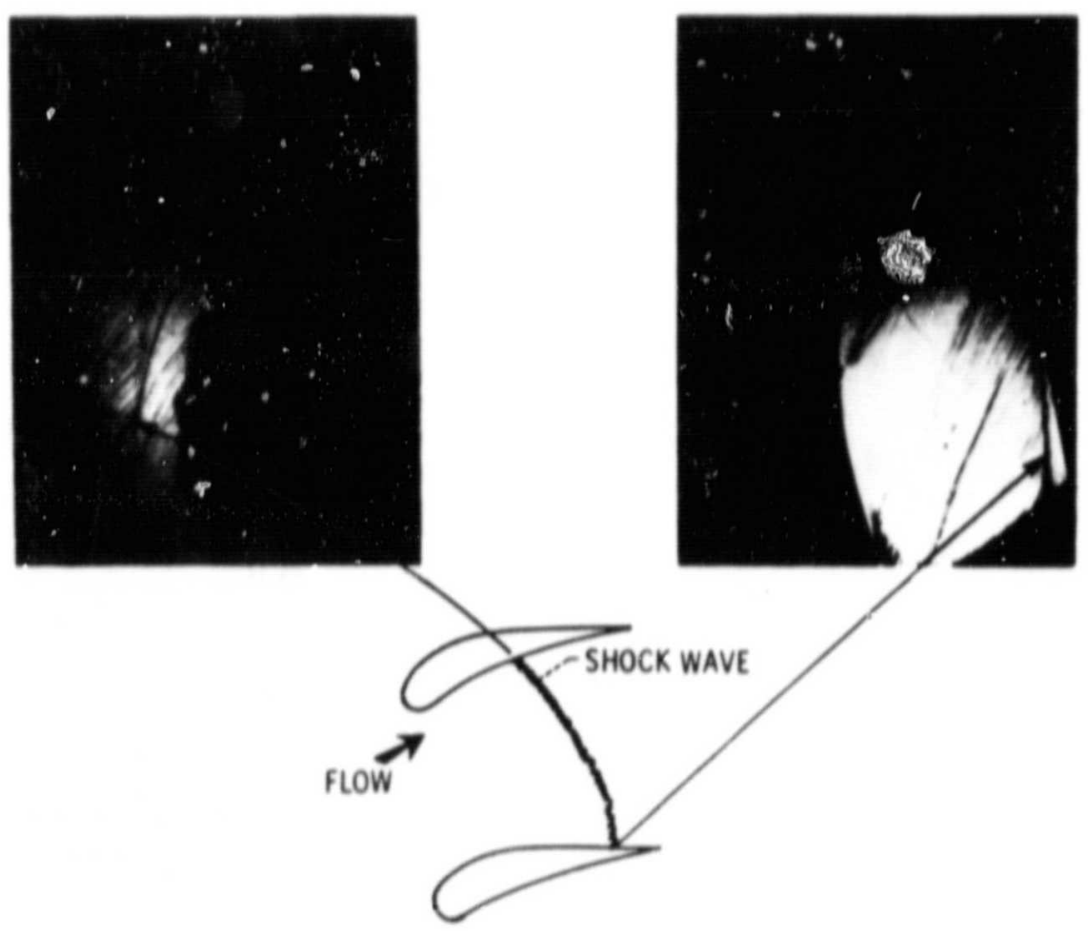

Figure 11. - Interblade shock structure on the 10-bladed $\mathbf{4 0}$ swept propeller at Mach 0.8. 


\section{ORIGINAL PAQE IS OF POOR QUALITY}

LIFTING LINE ANALYYSES

STRIP ANALYSIS - EXISTING

CURVED LIFTING LINE

PROPELLER/NACELLE

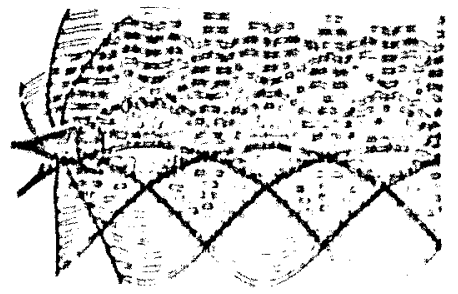

LIFTING SURFACE ANALYSES

EULER EQUATIINS

TRANSONIC POTENTIAL.

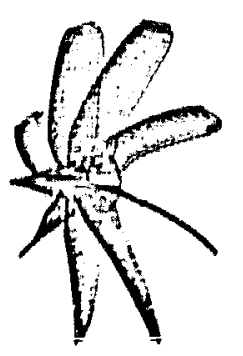

Figuro 12. - Advanced analysls methods for Improving propellor performance.
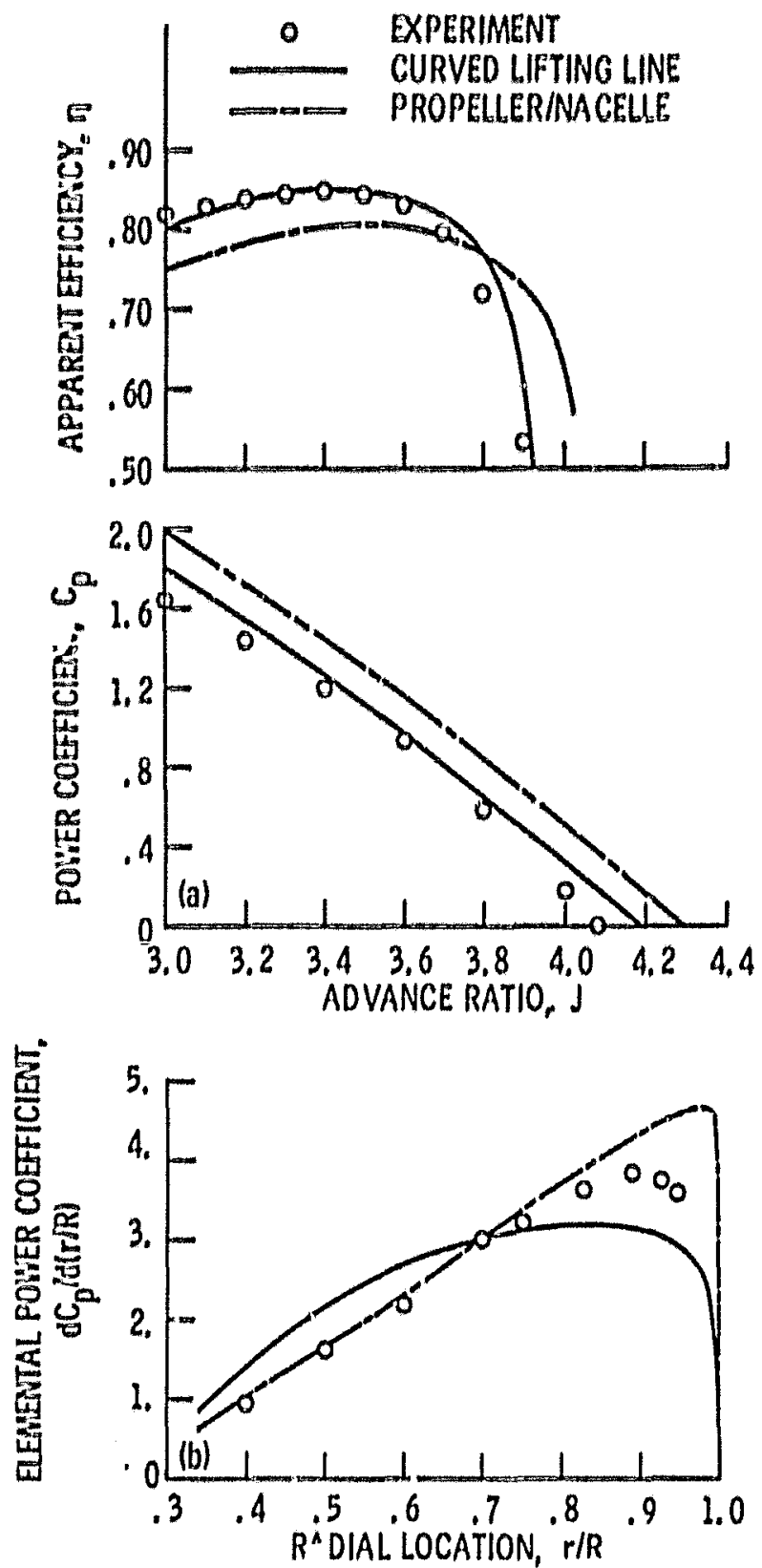

(a) Propeller performance. Blade angle at $3 / 4$ radlus equals $60.4^{\circ}$.

(b) Power loading distribution. Advance ratlo equals 3.06 .

Figure 13. - Comparison of analytical and experlmental results for the $S R-3$ propeller at free stream Mach number of 0.8 . Camber, drag, nonuniform inflow and centrifugal effect on twist included. 


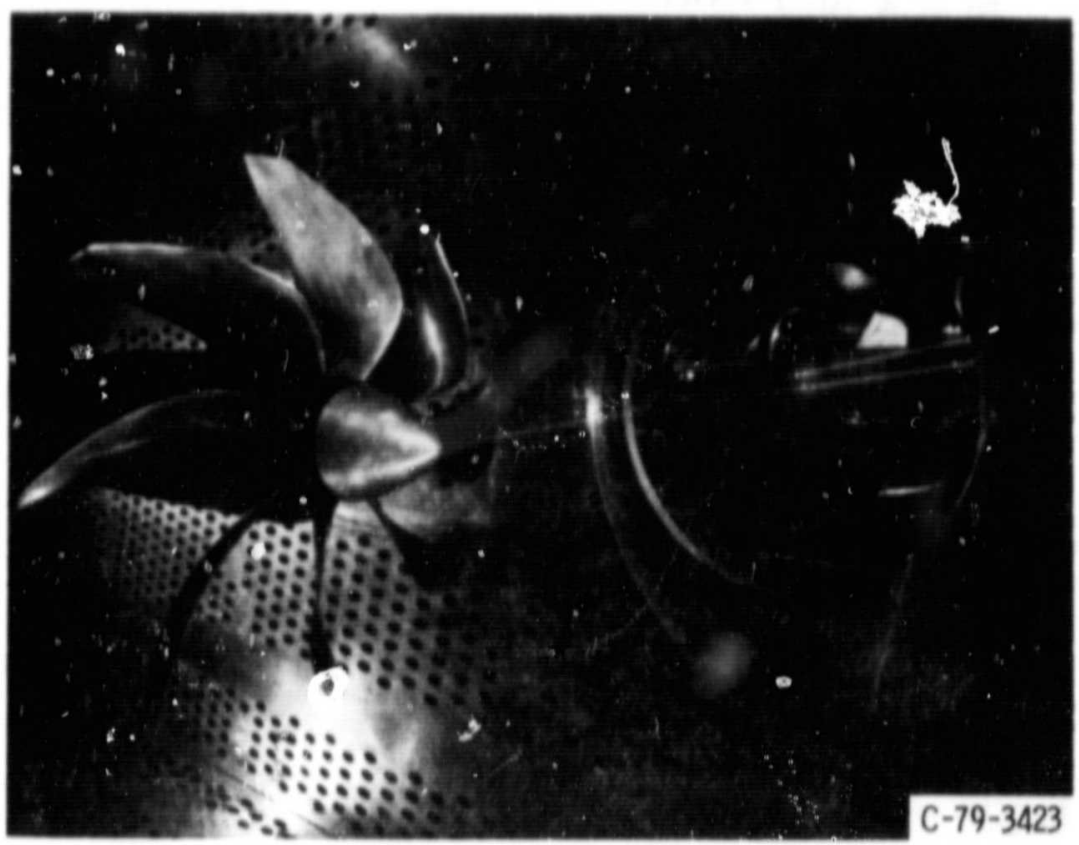

Figure 14, - Laser velocimeter in Lewis 8-by 6-toot wind tunnel.

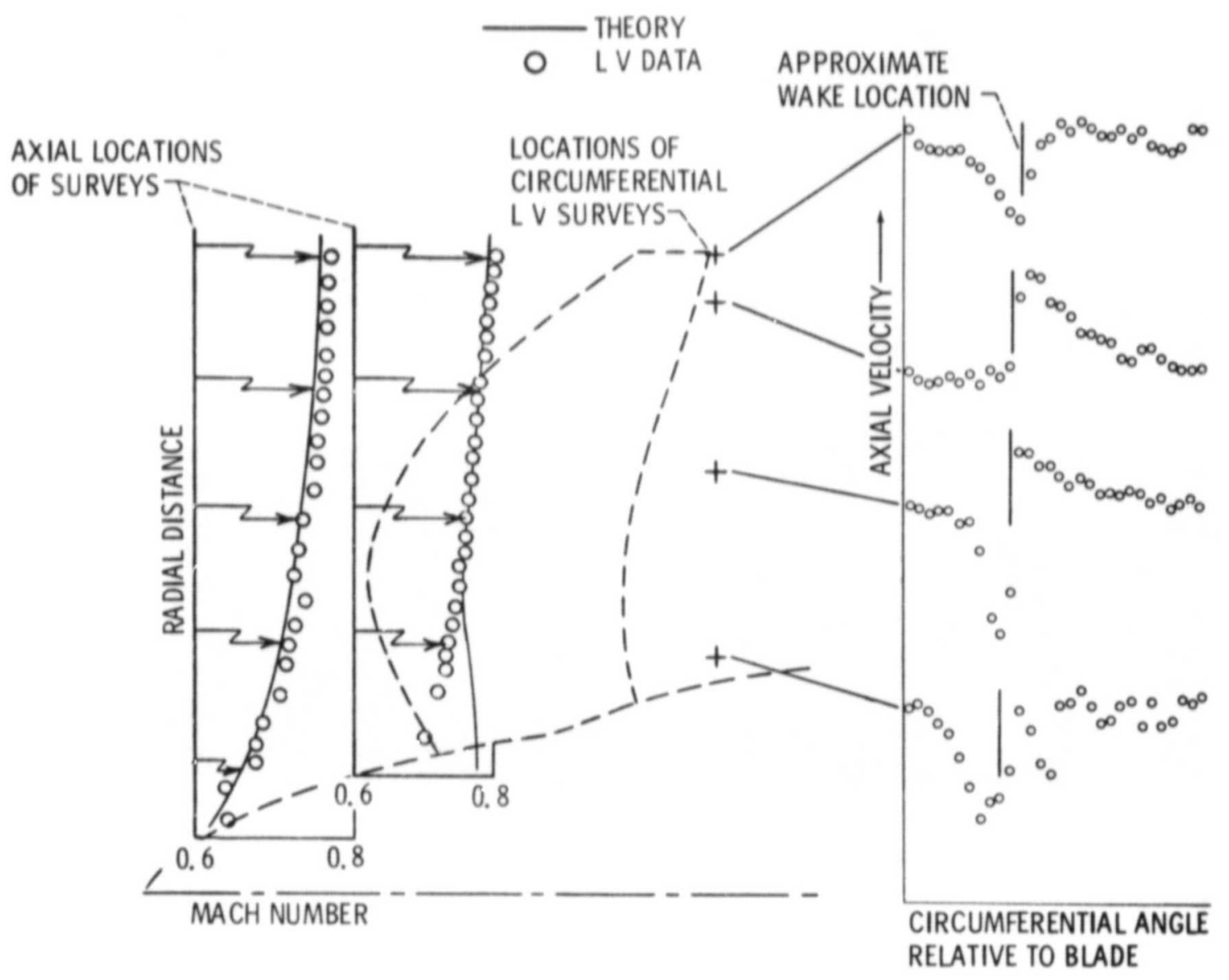

Figure 15. - Laser velocimeter (LV) velocity measurements of the 8 -bladed $45^{\circ}$ swept propc:ler (SR-3) flow field. 


\section{ORIGINAL PAGE \\ BLACK AND WHITE PHOTOGRAPH}

THIN AIRFOILS

HIGH BLADE SWEEP

HIGH BLADE LEAN

LOW ASPECT RATIO

HIGH SOLIDITY

TRANSONIC IIP SPEEDS

Figure 16, - Unconventional charact,ristics of advanced high-speed propellers contributing to aeroelastic uncertainty.

STALL FLUTTER

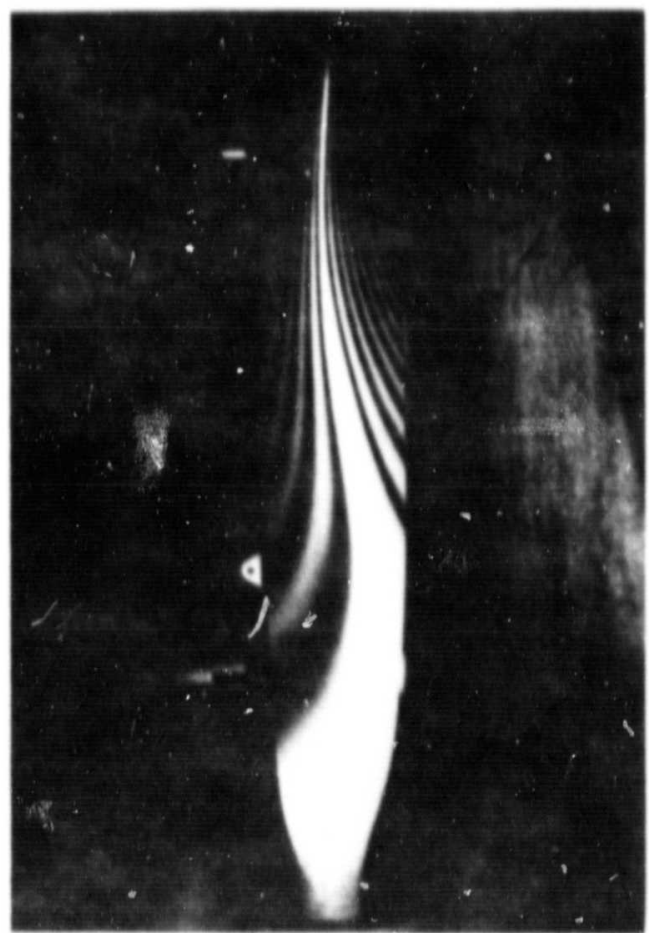

FORCED EXCITATION

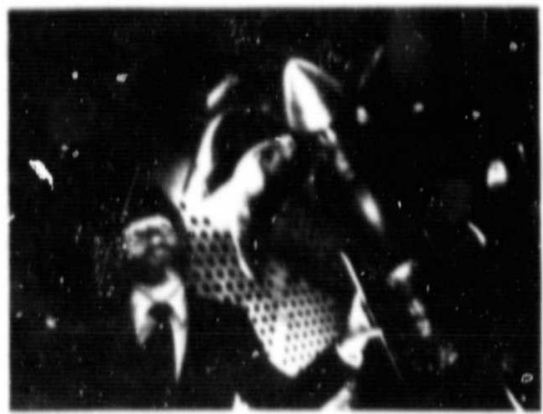

CLASSICAL FLUTTER

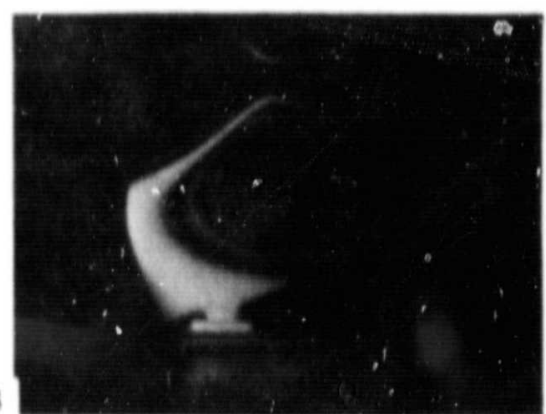

Figure 17. - Areas of propeller Aeroelastic Research. 


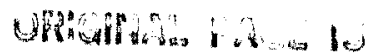

QP POCR QUALTY

\begin{tabular}{|c|c|c|c|c|}
\hline PROPELLER MODEL & $\begin{array}{l}\text { LOW SPEED } \\
\text { FLUTTER } \\
M=0 \text { TO } 0.4\end{array}$ & $\begin{array}{l}\text { HIGH SPEE:: } \\
\text { FLUTTER } \\
M=0.6 \text { TO } 0.85\end{array}$ & $\begin{array}{c}\text { ISOLATED } \\
\text { FORCED } \\
\text { EXCITATION } \\
M-0 \text { TO } 0.85\end{array}$ & $\begin{array}{c}\text { INSTALLED } \\
\text { FORCED } \\
\text { EXCITAFION } \\
M=0.3 \text { TO } 0.85\end{array}$ \\
\hline $\begin{array}{c}\text { SR-2 } \\
8 \text { BLADES, 0 SWEEP }\end{array}$ & $V^{\prime \prime}$ & $\checkmark$ & $\checkmark$ & $\checkmark$ \\
\hline $\begin{array}{c}S R-3 \\
8 \text { BLADES, } 45^{\circ} \text { SWEEP }\end{array}$ & $\checkmark^{\bullet}$ & $\checkmark$ & $\checkmark$ & PLAN \\
\hline $\begin{array}{c}S R-5 \\
10 \text { BLADES, } 60^{\circ} \text { SWEEP }\end{array}$ & $\vee^{\circ}$ & $\vee^{\bullet}$ & $\checkmark$ & -...... \\
\hline
\end{tabular}

- FLUTTER OR INSTABILITY EXPERIENCED

$\checkmark$ TEST COMPLETE

Figure 18. - High-speed propeiler aeroelastic test program.

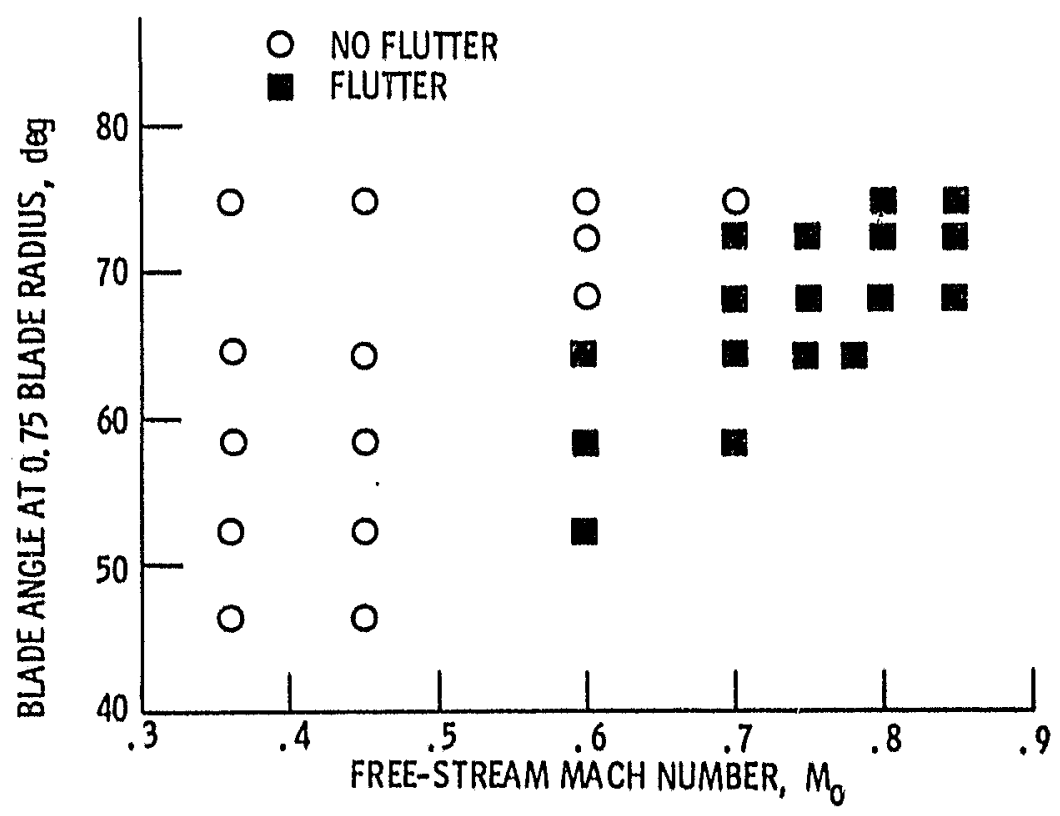

Figure 19. - Flutter envelope for the 10-bladed $60^{\circ}$ swept pro-peller (SR-5). 


\section{ORIGINAL PAGE IS ' \\ OF POOR QUALITY}

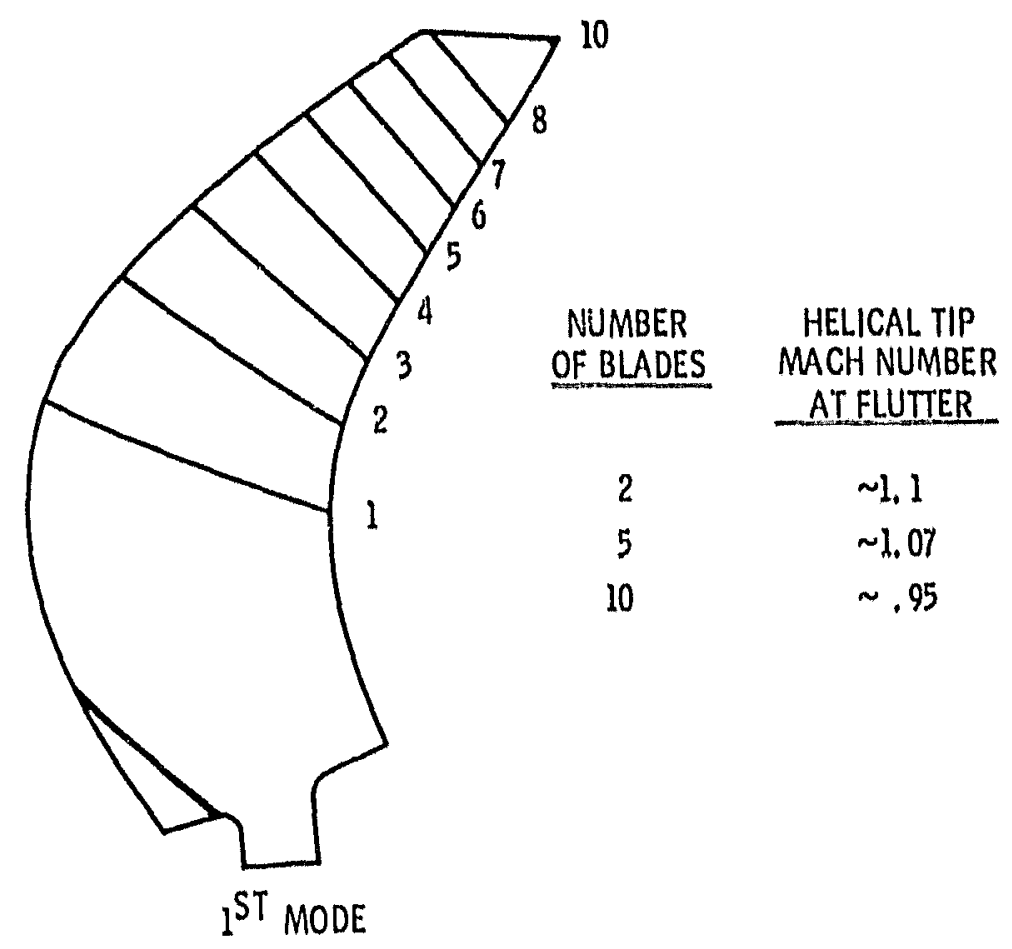

Figure 20, - Effect of blade number on the $60^{\circ}$ swept propeller model classical flutter, $M_{0}=0.6$ to 0.85 .

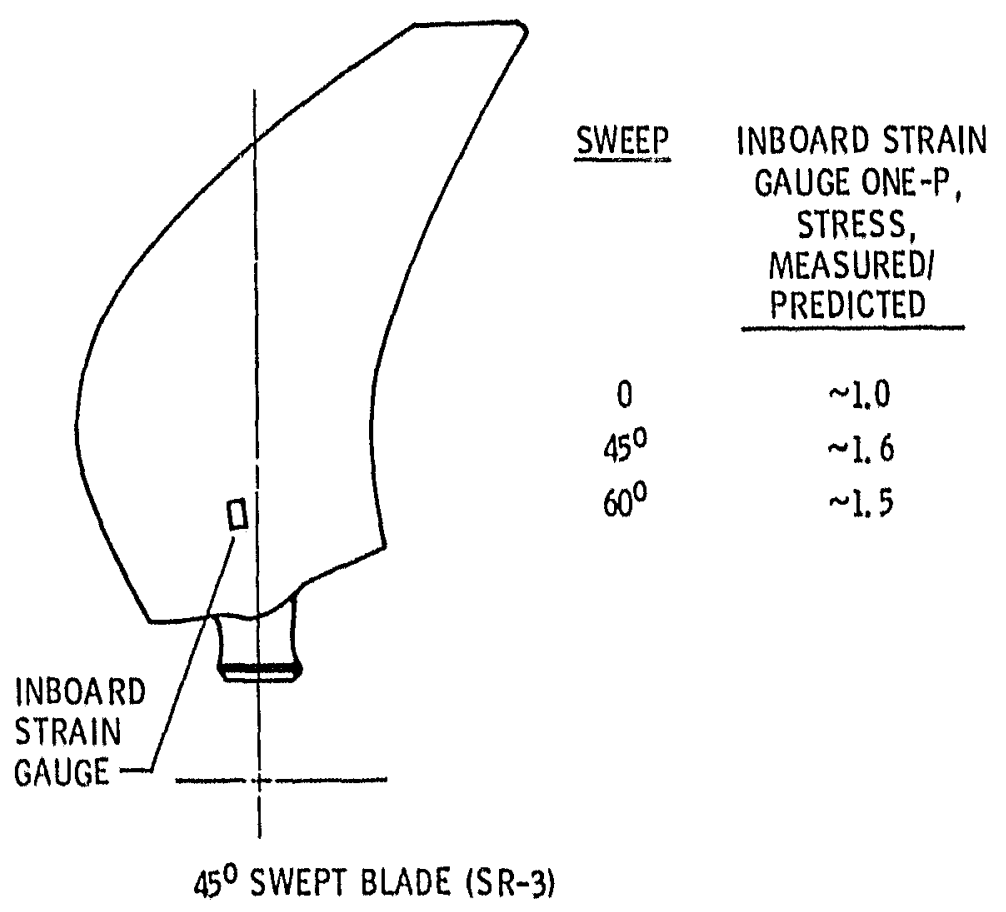

Figure 21. - Measured to predicted one-P stress ratio for advanced propeller models. 


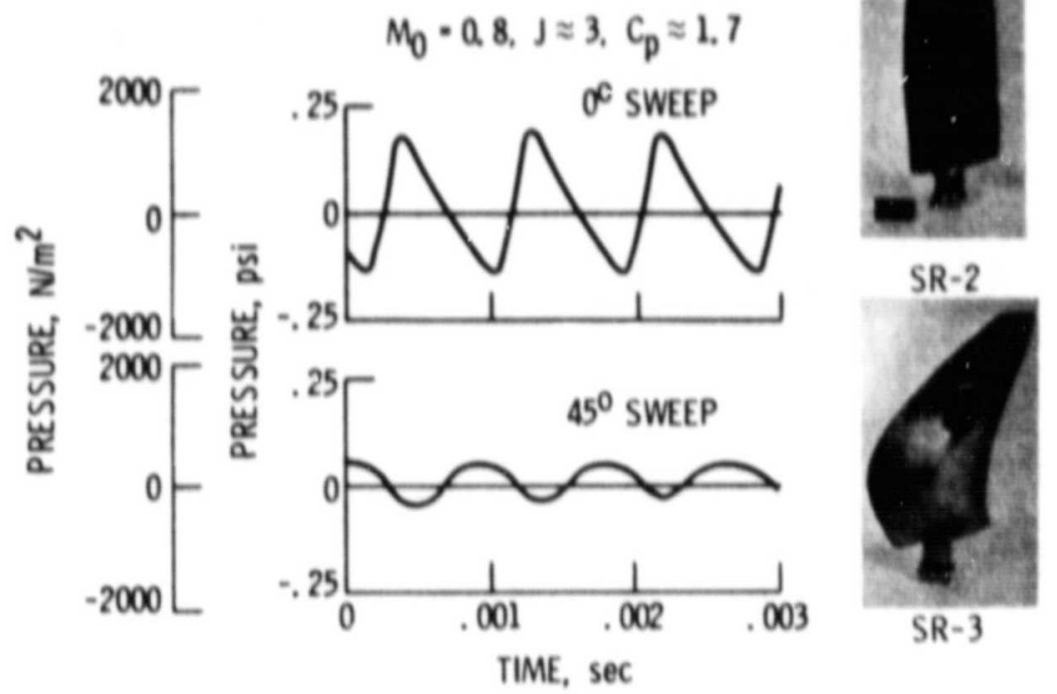

Figure 22. - Effect of sweep on measured near field acoustic pressure signature.

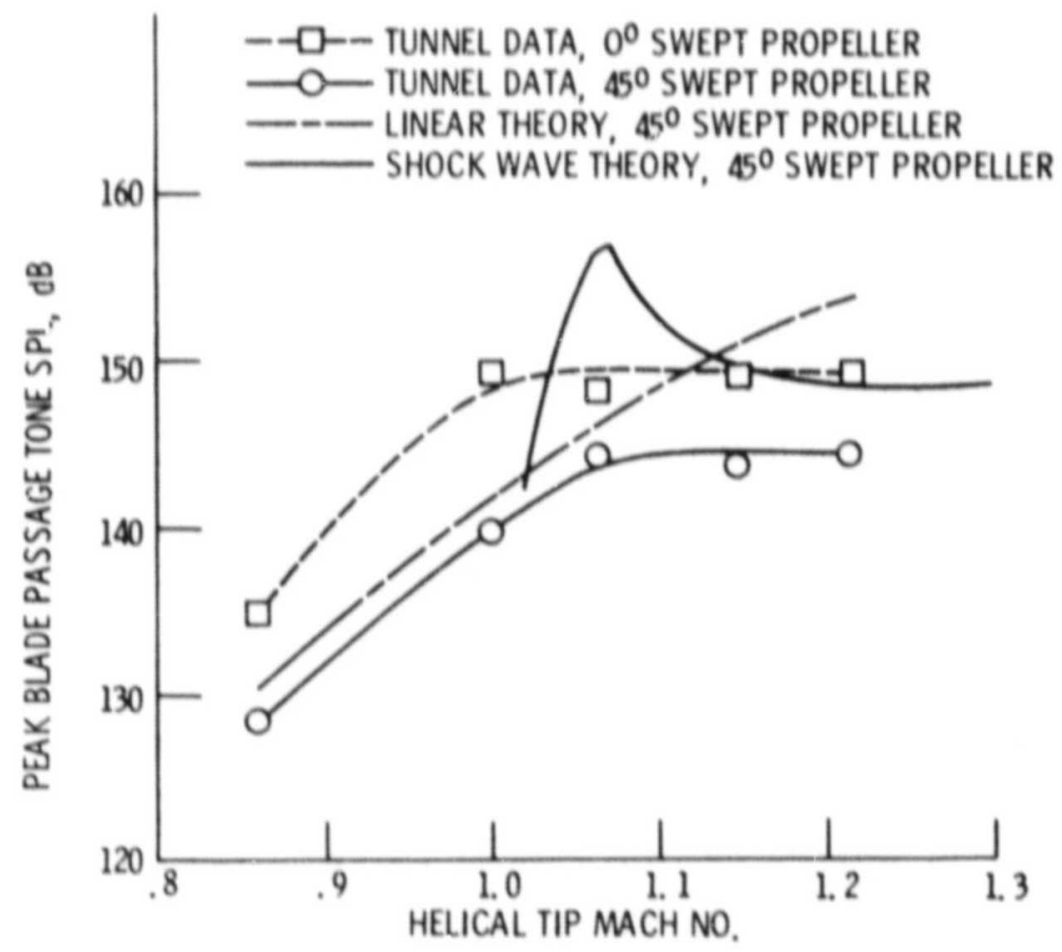

Figure 23. - Effect of blade sweep on near fieid noise of 8bladed propellers at 1.5 diameters from propeller tip. 


\section{ORIGINAL PAGE IS \\ OF POOR QUALITY}

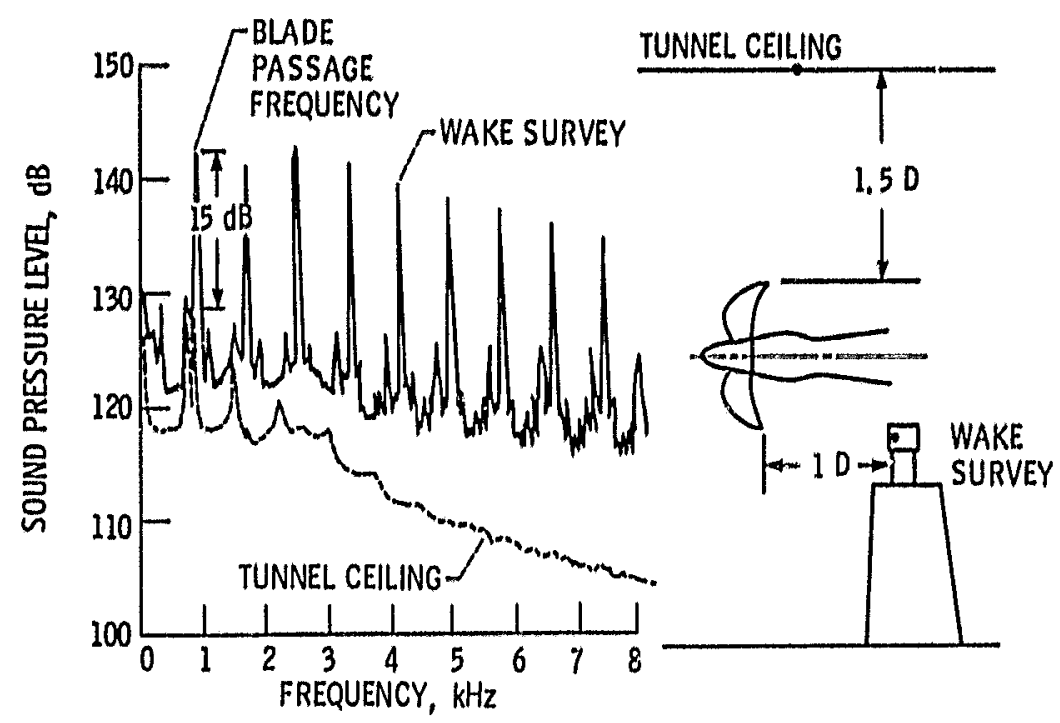

Figure 24, - Comparison of propeller direct radlated nolse and wake unsteady pressure, $M_{0}=0,6, J=3,06, C_{p}=1,84, M_{h t}=0,86$,

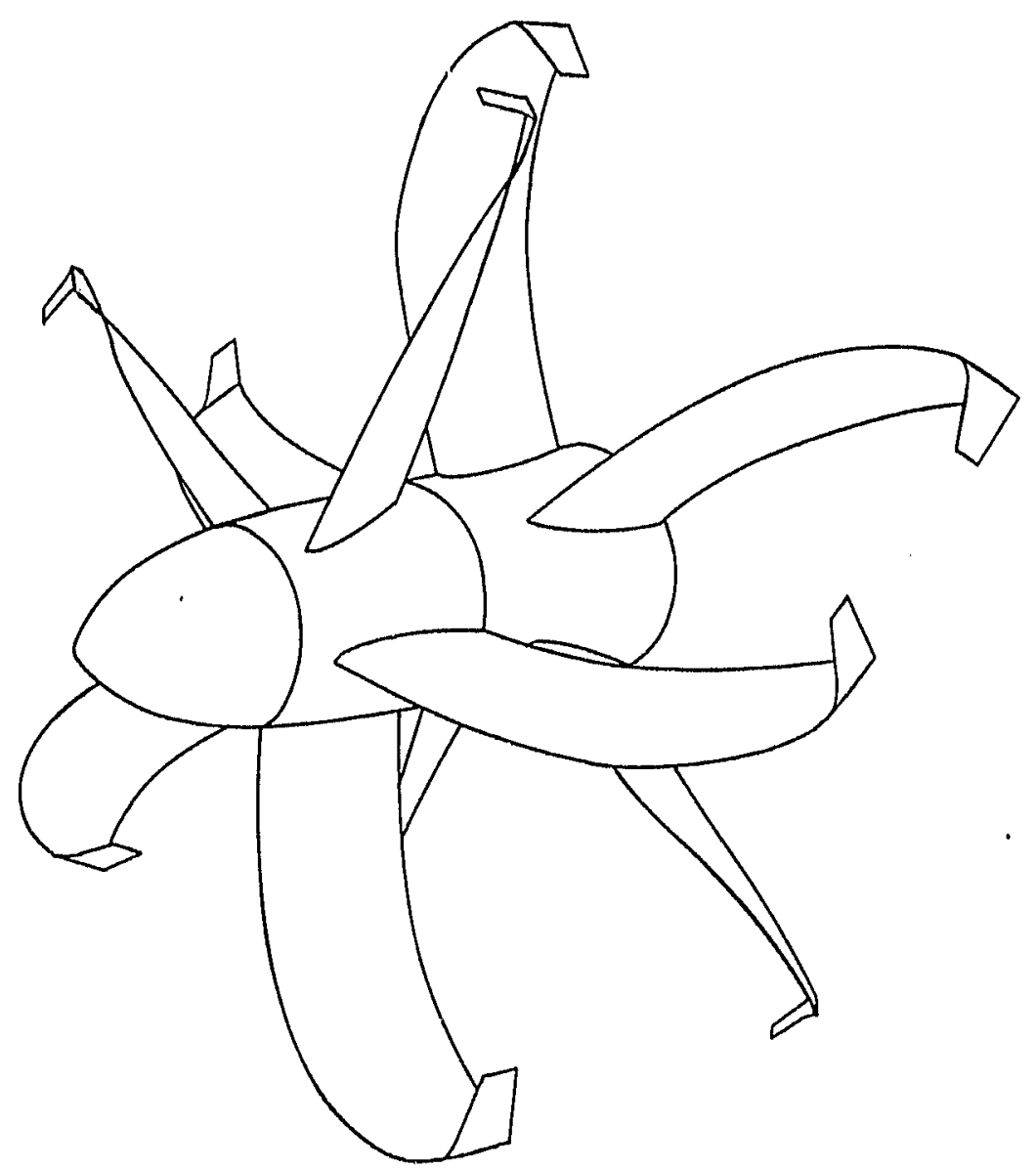

Figure 25. - Future advanced counter-rotation propeller concept. 
ORIGINAL PAGE IS

\section{OF POOR QUALITY}

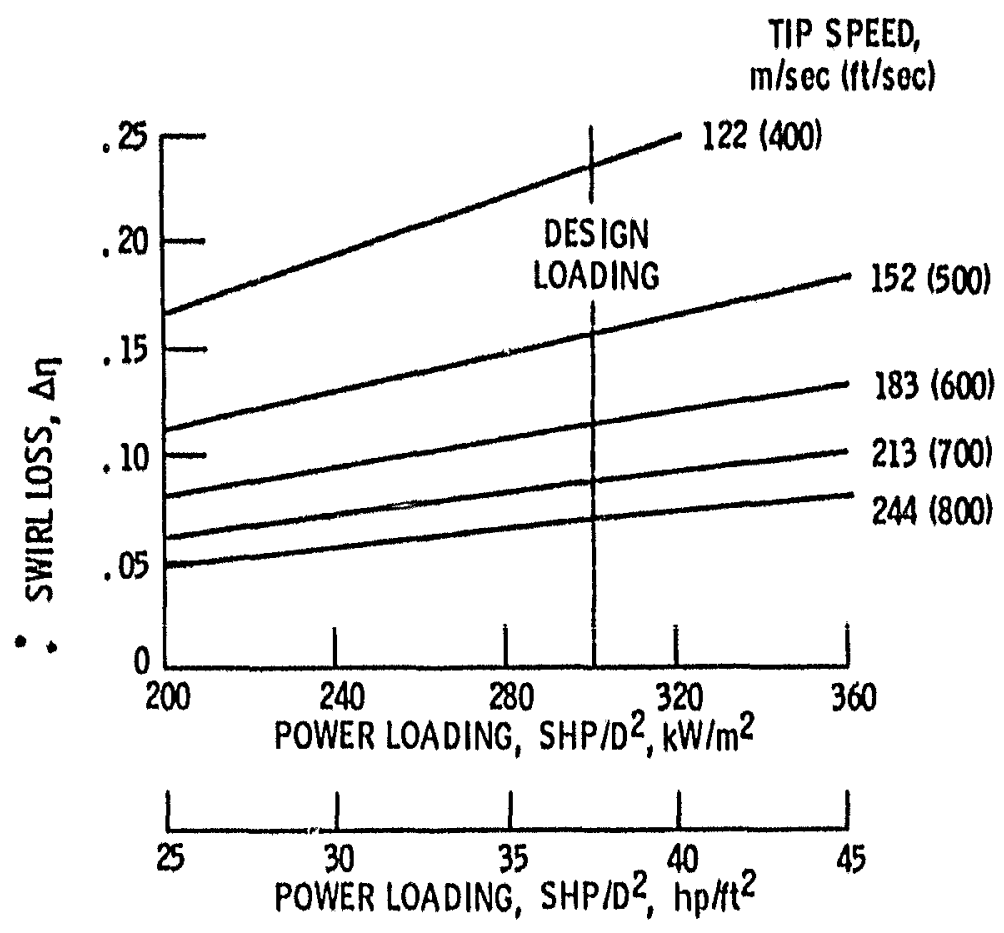

Figure 26. - Swirl loss of advanced single-rotation propellers, $M_{0}=0.8$, altltude $=10.668 \mathrm{~km}(35000 \mathrm{ft})$. 